\title{
Role of Common-Gamma Chain Cytokines in NK Cell Development and Function: Perspectives for Immunotherapy
}

\author{
Raffaella Meazza, ${ }^{1}$ Bruno Azzarone, ${ }^{2,3}$ Anna Maria Orengo, ${ }^{4}$ and Silvano Ferrini ${ }^{4}$ \\ ${ }^{1}$ Immunology Unit, Department of Translational Oncology, National Institute for Cancer Research, \\ Largo R. Benzi 10, 16132 Genoa, Italy \\ ${ }^{2}$ UMR 1014 INSERM, Building. Lavoisier, Paul Brousse Hospital, 94800, Villejuif, France \\ ${ }^{3}$ University Paris-Sud Paris XI, 91405 Orsay Cedex, France \\ ${ }^{4}$ Immunotherapy Unit, Department of Translational Oncology, National Institute for Cancer Research, \\ Largo R. Benzi 10, 16132 Genoa, Italy
}

Correspondence should be addressed to Silvano Ferrini, silvano.ferrini@istge.it

Received 28 January 2011; Accepted 14 March 2011

Academic Editor: Roberto Biassoni

Copyright (C) 2011 Raffaella Meazza et al. This is an open access article distributed under the Creative Commons Attribution License, which permits unrestricted use, distribution, and reproduction in any medium, provided the original work is properly cited.

NK cells are components of the innate immunity system and play an important role as a first-line defense mechanism against viral infections and in tumor immune surveillance. Their development and their functional activities are controlled by several factors among which cytokines sharing the usage of the common cytokine-receptor gamma chain play a pivotal role. In particular, IL-2, IL-7, IL-15, and IL-21 are the members of this family predominantly involved in NK cell biology. In this paper, we will address their role in NK cell ontogeny, regulation of functional activities, development of specialized cell subsets, and acquisition of memorylike functions. Finally, the potential application of these cytokines as recombinant molecules to NK cell-based immunotherapy approaches will be discussed.

\section{Background: The Common-Gamma Chain Cytokine Family}

Cytokines are soluble mediators of intercellular signals and play an essential role in the activation and regulation of both adaptive and innate immunity. In particular, the family of cytokines, sharing the common cytokine-receptor gammachain $\left(\gamma_{c}\right.$ or CD132) in their receptor complexes, consists of several members with a similar four alpha-helix bundle structure. This family comprises interleukin (IL)-2, IL-4, IL-7, IL-9, IL-15, and IL-21, which display functional redundancy in the regulation of the immune response and in the homeostasis of the lymphoid system but have also specific functions [1]. Each of these cytokines binds to a specific high affinity receptor complex formed by a cytokine-specific $\alpha$ chain and the $\gamma_{c}[2,3]$ (Figure 1). Different from other members of this family, IL-2 and IL-15 can bind with high affinity to heterotrimeric receptor complexes, which consist of IL-2R $\alpha$ (CD25) or IL15-R $\alpha$, respectively, and of
IL-2R $\beta(\mathrm{CD} 122)$ and $\gamma_{c}$ chains $[4,5]$. The $\gamma_{c}$ is an essential component of the receptors of all these cytokines, as it associates to the Janus tyrosine-kinase (JAK)-3, which is required for signal transduction [6]. JAK-3 phosphorylates different downstream signal transducer and activator of transcription (STAT) molecules, in relationship to the type of the receptor complex involved (Figure 1). Thus, IL-4 predominantly signals through STAT-6, whereas IL-2, IL-7, IL-9, and IL-15 mainly activate STAT-5, and IL-21 acts through STAT- 3 and STAT1 $[1,7]$. The activation of different STAT proteins by JAK-3 is related to its ability to phosphorylate the intracytoplasmic tail of different receptor chains. Tyrosinephosphorylation of aminoacidic motifs in cytokine-specific receptor molecules generates docking sites for specific unphosphorylated STAT monomers, which are recruited to the receptor complex through their $\mathrm{SH}-2$ domains [8]. Upon tyrosine phosphorylation by JAK-3, phosphorylated STAT molecules dimerize and migrate into the nucleus, where they bind to STAT-sensitive regulatory elements and control 


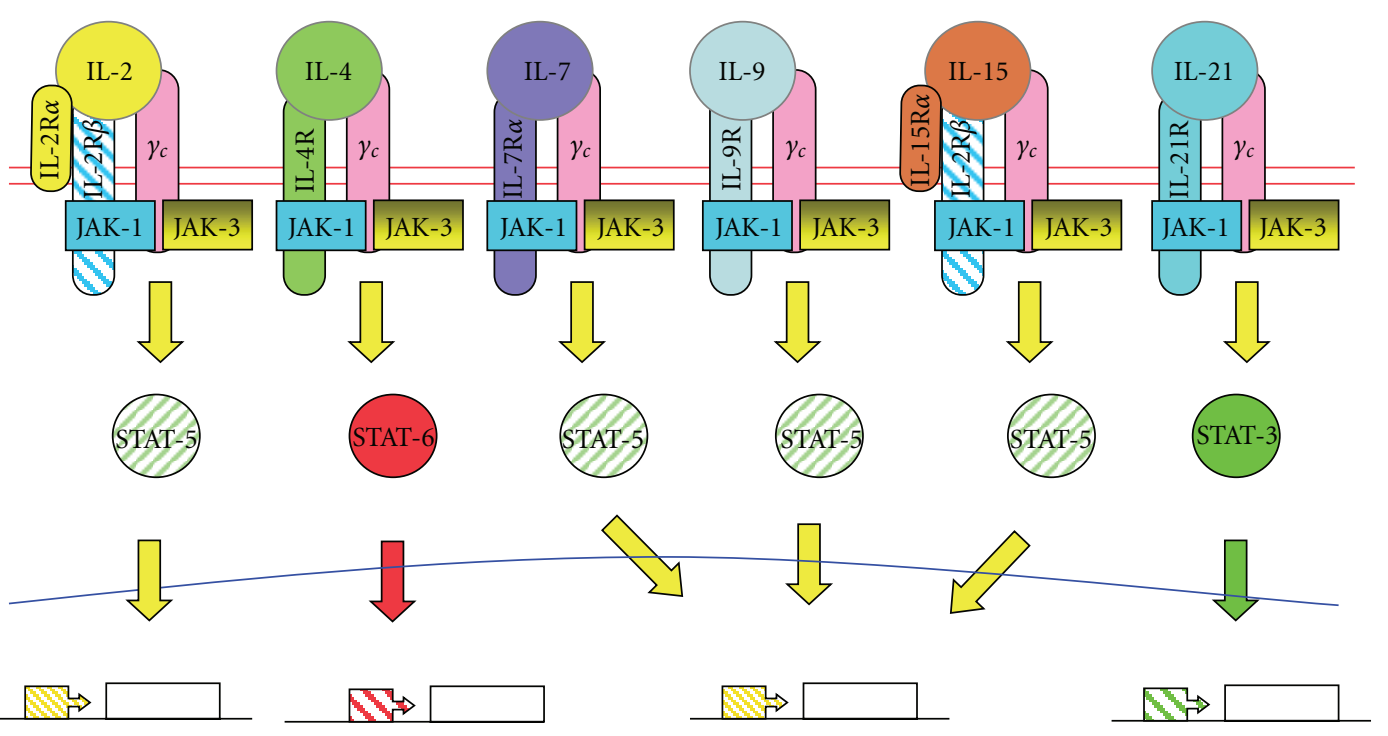

Interleukin-inducible genes

FIGURE 1: The family of cytokines sharing the common cytokine-receptor $\gamma_{c}$ in their receptor complexes. Each cytokine binds to a specific $\alpha$ chain, which forms a receptor complex with the $\gamma_{c}$. In case of IL-2 and IL-15, trimeric high affinity complexes, which include common IL-2R $\beta$ and $\gamma_{c}$ chains, can be formed. Each receptor complex mediates signal transduction through JAK1 and/or JAK3 and different STAT molecules. Tyr-phosphorylated STAT dimers regulate transcription of specific cytokine-sensitive genes.

transcription of specific genes. Both the $\gamma_{c}$ and JAK3 are essential for the function of all cytokine receptors of this family and are required for the development of the lymphoid cell system. Indeed, genetic defects of $\gamma_{c}$ or JAK-3 results in a severe combined immune deficiency (SCID) characterized by the lack of T, B, and NK cells in both mice and humans [9]. In addition to JAK-3, some receptor complexes also activate JAK-1, which predominantly phosphorylates STAT-1 molecules.

IL-2 is the firstly identified member of this cytokine family, and its gene was originally cloned on the basis of the T-cell growth factor (TCGF) activity of this cytokine $[10,11]$. Besides its TCGF activity, IL-2 upregulates NK cell proliferation and function, induces lymphokine-activated killer (LAK) activity, and also mediates activated B cell proliferation and Ig production [12]. IL-4 plays an important role in T helper (Th)2 cell development and function, in the regulation of $\mathrm{B}$ cell responses, and particularly in $\operatorname{IgE}$ production. Therefore, it is involved in allergic diseases and defense against parasitic infections [13]. Few effects of IL4 have been reported on NK cells. Recent data indicate that IL-4 downregulates the expression of the activating receptor NKG2D in mouse NK cells, thus inhibiting NKG2Ddependent killing in vitro and in vivo [14]. In addition, IL4 can also inhibit Ly49 receptors expression [15], suggesting a functional role in the innate immunity response. Finally, human NK cells cultured for short term with IL-4 did not release interferon (IFN) $-\gamma$ and showed no cytolytic activity in response to stimulation through NKp46-activating receptor. In contrast, IL-12-cultured NK cells released IFN- $\gamma$ and displayed strong cytolytic activity against tumor cells or immature dendritic cells (DC). These data suggest that IL-4 may negatively influence the NK/DC cross-talk, impair Th1 priming, and favor tolerogenic or Th2 responses in humans [16]. Different from the two previous cytokines, which mainly regulate the immune response, IL-7 is fundamental for the homeostasis of the immune system, as it regulates T, B, and NK lymphoid cell development [17]. Indeed, IL-7 is produced by thymic and bone marrow epithelial and stromal cells and by reticular cells in peripheral lymphoid tissues. IL-7 supports differentiation of hematopoietic stem cells into lymphoid progenitor cells and proliferation and survival of lymphoid precursor cells in the bone marrow and in the thymus. In addition, it stimulates survival of naive and memory $\mathrm{T}$ cells in the periphery. The crucial role of IL-7 in lymphoid cell development is clearly evidenced by the $\mathrm{T}$ and B-cell deficient SCID phenotype of patients and mice with genetic defects of the IL-7R $\alpha$ (CD127) chain $[16,18]$. Although IL-7R $\alpha$-deficient patients and mice do not have NK cell deficiency, several data indicate that IL-7 is involved in the development of specific subsets of NK cells [19-24]. IL-9 is a proinflammatory cytokine released by activated $\mathrm{CD} 4^{+} \mathrm{T}$ cells and mediates activation of eosinophils, mast-cells, and bronchial epithelial cells, thus playing a relevant role in asthma [25]. However, IL-9 appears not involved in NK cell regulation. IL-15, instead, plays a pivotal role in NK cell biology. This cytokine shares several functional activities of IL-2 due to the promiscuous usage not only of the $\gamma_{c}$, but also of the IL-2R $\beta$ chain $[4,12,26]$. However, differently from IL-2, IL-15 is expressed in several tissues and it is produced by different nonlymphoid cell types such as monocytes, DC and stromal cells of the bone marrow and thymus [5]. IL-15 produced in bone marrow, thymus, and secondary lymphoid organs is a crucial element to drive the development and 
survival of NK cells [27-29] and of certain subsets of T cells $[27,28]$. Finally, IL-21, the most recently identified member of this cytokine family [30] was originally discovered as the ligand of an IL-2R $\beta$-related orphan receptor [31], now termed IL-21R. IL-21 can costimulate the proliferation of T, $\mathrm{B}$, and NK cells and promotes the terminal differentiation of IL-15 activated NK cells and of activated B cells into plasma cells [32]. In addition, IL-21 mediates apoptosis of partially activated normal B cells [33] and of certain human neoplastic B cells [34-37].

This paper will focus on the role of IL-2, IL-7, IL-15, and IL-21 in NK cell development and function and will discuss the possible relevance of NK activation by these cytokines in cancer immunotherapy.

\section{Distinct Role of IL-2 and IL-15 in NK Cell Biology}

IL-2 and IL-15 share several functional properties in relationship to the use of two promiscuous receptor components (IL$2 \mathrm{R} \beta$ and $\gamma_{c}$ ) and common signaling pathways. Indeed, both cytokines stimulate the proliferation, survival, and functional activities of $\mathrm{NK}$ cells and activated $\mathrm{T}$ and $\mathrm{B}$ cells. Nonetheless, the two cytokines have also specific functions, which are related to the different cellular distribution and functional properties of the IL-2R $\alpha$ and IL-15R $\alpha$ chains and the to the distinct cellular origin and regulation of IL-2 and IL-15 production [12].

IL-2 may act through two types of receptor complexes: the high affinity trimeric receptor formed by IL-2R $\alpha$, IL-2R $\beta$, and $\gamma_{c}$ and an intermediate affinity dimeric receptor formed by the IL-2R $\beta$ and $\gamma_{c}$. While the high affinity trimeric receptor is expressed on activated $\mathrm{T}$ and $\mathrm{NK}$ cells, the intermediate receptor is constitutively expressed on $\mathrm{CD}^{-} \mathrm{CD} 56^{+} \mathrm{CD} 16^{+}$ NK cells [38] and on minor subsets of T cells, which can directly respond to high concentrations of IL-2. The constitutive expression of functional IL-2R accounts for the induction of LAK cells, displaying broad non-MHC restricted cytolytic activity against different types of tumor cells by short-term culture of PBMC in IL-2-containing medium [39]. Indeed, LAK cells are predominantly represented by IL-2-activated NK cells and by a subset of T cells [40]. However, a subset of human $\mathrm{CD}^{-} \mathrm{CD} 56^{\text {bright }} \mathrm{CD} 16^{-} \mathrm{NK}$ cells constitutively express high affinity IL-2 receptors and may respond to low IL-2 concentrations [41, 42].

The IL- 2 and IL- 15 receptor $\alpha$ chains display remarkable differences. IL-2R $\alpha$ alone has a low affinity for IL-2 and is devoid of signaling properties although it is required for the generation of high-affinity trimeric IL-2R complexes. IL-2R $\alpha$ expression is induced in $\mathrm{T}$ cells upon activation; however, it is constitutively expressed at high levels on immune suppressive $\mathrm{CD} 4{ }^{+} \mathrm{CD} 25^{+} \mathrm{FoxP}^{+}$regulatory $\mathrm{T}$ (Treg) cells [43]. Indeed, IL-2 plays a specific role in immune regulation and in peripheral tolerance [44], as it is involved in the maintenance and fitness of $\mathrm{CD}^{+} \mathrm{CD} 25^{+} \mathrm{FoxP}^{+}$Treg cells $[45,46]$. In addition, IL-2 participates in activation-induced cell death of $\mathrm{T}$ cells, which limits $\mathrm{T}$ cell responses [47]. The primary role of IL-2 in immune regulation is evidenced by the study of mice defective of IL-2 [48] or of IL-2R $\alpha$ [49] genes, which develop a lymphoproliferative disorder associated with autoimmunity and impaired Treg function. The genetic defect of the IL-2R $\beta$ chain results in autoimmunity in mice and also in a unique NK-deficient immunophenotype in mice [50] and humans [51]. In addition, an NK cell defect is part of the SCID phenotype in humans [52] and mice [53] bearing genetic defects of the $\gamma_{c}$. Altogether, these studies indicated that IL- 2 or IL-2R $\alpha$ are not necessary for NK cell development, although the IL-2R $\beta$ and the $\gamma_{c}$ are strictly required, suggesting a role for IL-15. Indeed, IL-15 and its specific receptor IL-15R $\alpha$ are essential for the generation and maintenance of NK cells, as IL-15 mediates the development of NK cells from committed NK cell precursors, promotes the differentiation of immature NK cells, and supports the survival of mature NK cells in the peripheral lymphoid organs [54-56].

Different from IL-2R $\alpha$, IL-15R $\alpha$ alone has a high affinity for IL-15 and is constitutively expressed in several lymphoid and nonlymphoid cell types [57, 58]. The study of IL15- [28] or IL-15R $\alpha$-KO [27] mice, which have similar NK-deficient phenotypes, confirmed that the IL-15/IL-15R $\alpha$ system has an unique essential role in the development and survival of NK cells and of certain subsets of T cells such as NKT cells and intestinal intraepithelial CD8 $\alpha \alpha^{+} \mathrm{T}$ cells. In addition, IL-15R $\alpha$ deficient mice have a reduced $\mathrm{CD} 8{ }^{+} \mathrm{CD} 44^{\text {high }}$ memory $\mathrm{T}$ cell pool, indicating a critical role of this receptor in the maintenance of a CD8 memory.

Similar to IL-2, IL-15 can mediate conversion of poorly cytolytic resting NK cells into highly cytolytic effector NK cells, which acquire enhanced antitumor activity [59]. Resting murine NK cells contain abundant granzyme A, but little granzyme $\mathrm{B}$ or perforin while the mRNAs for all three genes are highly expressed. IL-2 or IL-15 mediate a dramatic increase in granzyme B and perforin proteins without altering their mRNA abundance. These data suggest that these cytokines can mediate the removal of a block of perforin and granzyme B mRNA translation that prevents resting NK cells to be fully cytotoxic [60].

Several evidences indicate that IL-15 supports NK cell survival $[12,29]$ and is more potent than IL-2 in this respect. The antiapoptotic effects of IL-15 on murine NK cells are mediated through the inhibition of Bim expression by different mechanisms involving Erk-1/2 phosphorylation or the phosphatidylinositol-3-OH kinase (PI(3)K)-dependent inactivation of the transcription factor Foxo3a. In addition, IL15 also promotes NK cells survival by the upregulation of Mcl-1, a molecule that was previously reported to be required for the development and survival of $\mathrm{T}$ and $\mathrm{B}$ lymphocytes [61].

Recent observations indicate that IL-2 or IL-15-activated NK cells display a different sensitivity to corticosteroids. The corticosteroid methylprednisolone inhibited the surface expression of the activating receptors NKp30 and NKp44 and cytolytic activity in IL-2- or IL-15-cultured human NK cells. However, proliferation and survival were inhibited in IL-2- but not in IL-15-cultured NK cells. Moreover, methylprednisolone inhibited activation of STAT-1, STAT3 , and STAT-5 in IL-2-cultured NK cells but only partially in 
IL-15-cultured NK cells. This study indicates a distinct ability of IL-15-cultured NK cells to survive to steroid treatment, an observation that is important in immune disorders requiring this drug [62].

Other important differences between IL-2 and IL-15 concern their regulation of expression and secretion. IL-2 gene is transcriptionally activated in Th cells in response to antigen presentation, and then activated Th cell release soluble IL-2, which can activate lymphoid cells expressing high or intermediate affinity receptor complexes. By contrast, IL-15 gene is constitutively expressed in several normal cell types, such as monocytes, DC, stromal cells, epithelial cells and also in some human neoplastic cells $[5,63]$. Two IL15 mRNA isoforms generated by alternative splicing have been identified in human cells: one encodes for a short signal peptide (SSP)-IL-15 and the other for a long-signal peptide (LSP)-IL-15 isoform [64, 65]. The two isoforms show a different intracellular trafficking, as the SSP-IL-15 predominantly localize to the cytoplasm and nucleus, whereas the LSP-IL-15 enters in the endoplasmic reticulum [66]. As a consequence the SSP-IL-15 isoform is not secreted and may have regulatory intracellular functions, whereas the LSPIL-15, which is usually more expressed, can be potentially exported outside the cell. Nonetheless, it appeared that only very limited amounts of IL-15 are secreted by IL-15 mRNA-expressing cells, possibly in relationship to its low translational rate, to inefficient secretion, and/or to putative retention motifs in the $\mathrm{COOH}$ terminus [65-68]. Thus, multiple mechanisms may regulate IL-15 production and secretion.

\section{Role of Cytokines in NK Cell Interactions in Secondary Lymphoid Organs}

The expression of IL-15 in stromal cells of primary and secondary lymphoid organs and the deficiency of NK cells in mice with genetic defects of the IL-15/IL-15R system indicate a primary role of IL-15 in NK cell development and homeostasis [69-71]. Nonetheless, several data support an important role of a DC/NK cell cross-talk, primarily mediated by cytokines, in the immune response and defense against pathogens in mice [72] and humans [73]. In bacterial infections the interaction between human NK and DC cells may lead to NK cell proliferation, activation, and cytolytic activity [73].

Stimulation in vitro with IL-15, IL-2, IL-1 or IL-18 or engagement of activating receptors (i.e., CD16 or NKG2D) in combination with IL-12 induces production of IFN- $\gamma$ and of other proinflammatory cytokines and chemokines, such as tumor-necrosis factor (TNF)- $\alpha$ and macrophage inflammatory protein (MIP)- $1 \alpha$ by human NK cells $[74,75]$. It is of note that cytokines that co-activate $\mathrm{NK}$ cells may be produced by monocytes/macrophages or DC and, in this context, it has been shown that DCs colocalize with NK cells in the T cell areas of lymph nodes. Membrane-bound IL-15 is highly exspressed on human DCs activated through CD40 engagement, and is essential for NK cell proliferation and survival. Thus, secondary lymphoid organs are important sites for DC/NK cell interactions [76].

Human $\mathrm{CD}^{-} \mathrm{CD}^{-} 6^{+} \mathrm{NKp} 46^{+} \mathrm{NK}$ cells are a heterogeneous cell population. The $\mathrm{CD} 56^{\mathrm{dim}} \mathrm{CD} 16^{+}$cells, predominant in peripheral blood, were originally described as strong cytotoxic effectors with low ability to produce cytokines, by contrast, the $\mathrm{CD} 56^{\text {bright }} \mathrm{CD} 16^{-} \mathrm{NK}$ cell subset, the most represented in secondary lymphoid organs, has been reported to be the most potent producer of IFN- $\gamma$ but provided of low cytolytic activity [77]. A recent study of De Maria et al. [78] reevaluated the functional capabilities of the two major human NK subsets and showed that NKp46 and NKp30-mediated stimulation induces an early (at 2-4h from stimulation) and abundant production of IFN- $\gamma$ by $\mathrm{CD}^{2} 6^{\mathrm{dim}} \mathrm{CD} 16^{+} \mathrm{NK}$ cells in relationship to the constitutive expression of IFN- $\gamma$ mRNA. However, IFN- $\gamma$ production was transient and no more cytokine production by this cell subset is observed after $16 \mathrm{~h}$ from stimulation, when $\mathrm{CD} 56^{\text {bright }} \mathrm{CD} 16^{+/-}$cells begin to release IFN- $\gamma$. IFN$\gamma$ production by the two NK subsets is also observed upon exposure to cytokine combinations such as IL-12+IL-2 or IL-12+IL-15. In this case, CD56 ${ }^{\mathrm{dim}} \mathrm{CD} 16^{+} \mathrm{NK}$ cells show early but persistent response to stimulation. Therefore, $\mathrm{CD}_{56}{ }^{\text {bright }} \mathrm{CD} 16^{+} \mathrm{NK}$ cells may play an important role in the early phases of innate responses and in the cross-talk with DC.

Different from CD56 $6^{\text {dim }}$, CD56 $6^{\text {bright }}$ NK cells constitutively express the high-affinity heterotrimeric IL-2 receptor complex $[41,42]$ and can, therefore, respond to picomolar concentrations of IL- 2 produced by Th cells. Costimulation of CD56 $6^{\text {bright }}$ human NK cells with IL- 2 and IL-12 produced by DC triggers the production of IFN- $\gamma$ [75]. IFN- $\gamma$ can further activate DCs and influence the polarization of the Th cell response to Th1. In addition, activated NK cells also produce TNF- $\alpha$ and granulocyte-macrophage colonystimulating factor (GM-CSF), which support DC differentiation and maturation. Therefore, CD56 ${ }^{\text {bright }} \mathrm{NK}$ cells may link the innate- and antigen-specific immune response, through an NK/DC cross-talk, and shape the adaptive immune response $[79,80]$.

\section{Involvement of Trans-Presentation in IL-15 Activity}

The lack of detectable IL-15 secretion, in contrast with its trafficking from the secretory compartment to the early endosomes in some IL-15-expressing human melanoma cells, suggested a possible juxtacrine activity of IL-15. In this early model, IL-15-mediated effects required cell to cell proximity (Figure 2 ) and could be blocked by an anti-IL-15 monoclonal antibody (mAb) [81]. Further studies showed that IL-15 is expressed as membrane-bound molecule in IFN- $\gamma$-stimulated human monocytes, which are capable to stimulate $\mathrm{T}$ cell proliferation [82]. In addition, IL-15mediated proliferation of mouse $\mathrm{T}$ cells, triggered by Poly I:C, did not require IL- $15 \mathrm{R} \alpha$ on the $\mathrm{T}$ cells but instead was dependent on the IL- $15 \mathrm{R} \alpha$ present on surrounding cells [83]. These findings could be later explained by the 


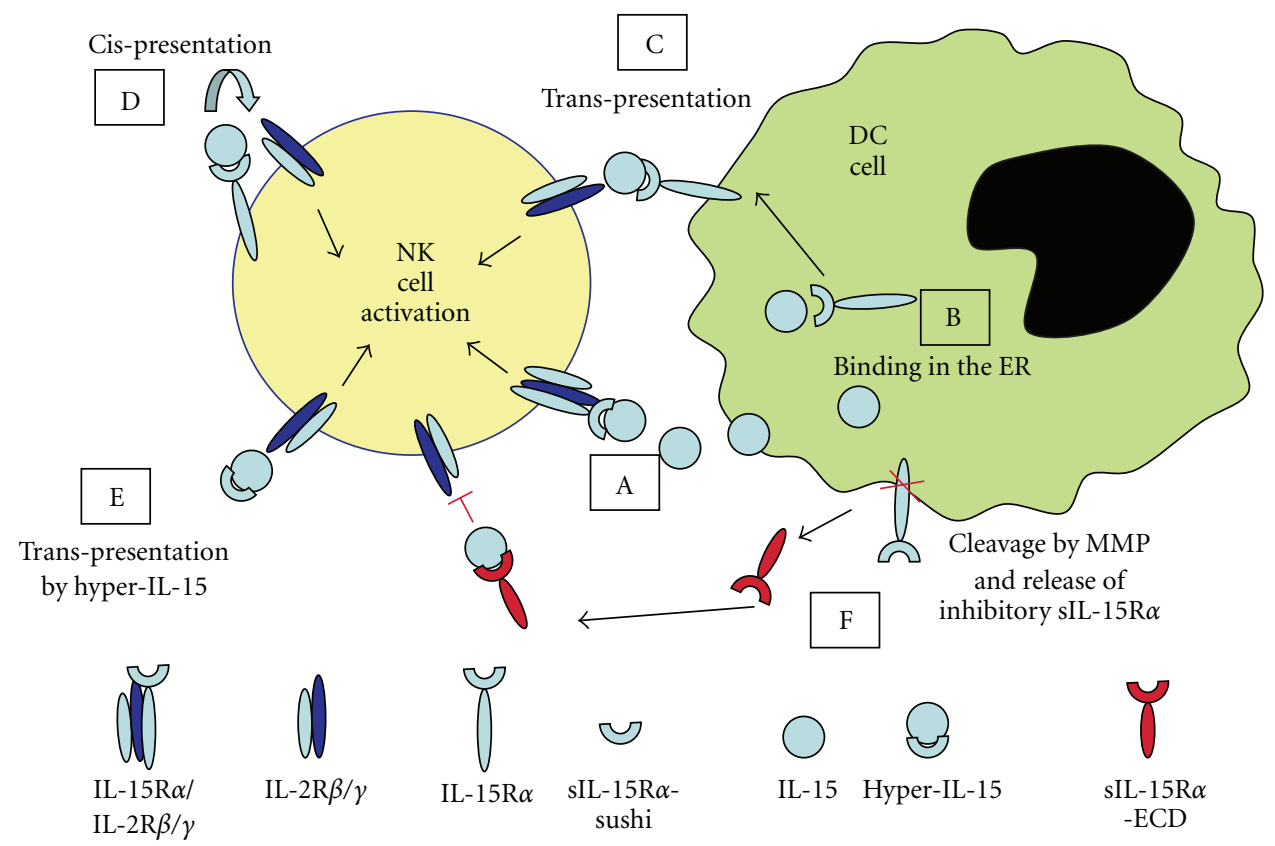

FIGURE 2: Different mechanisms of IL-15 action. (a): Low levels of secreted IL-15 can bind to high affinity trimeric receptors through a juxtacrine mechanism. (b): IL-15 binds to the high-affinity IL-15R $\alpha$ chain within the endoplasmic reticulum and is then shuttled to the cell membrane as a complex. (c): IL-15R $\alpha$ can trans-present IL-15 to an apposing IL-2R $\beta / \gamma_{c}{ }^{+}$NK cell through cell contact. (d): The possibility of cis-presentation by IL-15R $\alpha / \mathrm{IL}-15$ membrane complex to an IL-2R $\beta / \gamma_{c}$ heterodimer on the same NK cell is shown. (e): A soluble sushi domain-IL-15R $\alpha$ bound to IL-15 can perform trans-presentation in a soluble form. (f): Soluble IL-15R $\alpha$ extracellular domain generated by metalloprotease cleavage can bind soluble IL-15 and block its function.

trans-presentation of IL-15 through IL-15R $\alpha$. For transpresentation, exogenous IL-15 binds to cell surface IL$15 \mathrm{R} \alpha$ chain, the complex is internalized, recycled at the cell membrane and trans-presented to apposing T cells expressing IL-2R $\beta / \gamma_{c}$ heterodimers (Figure 2(c)) [84]. Alternatively, endogenously produced LSP-IL-15 binds into the endoplasmic reticulum with IL-15R $\alpha$, is exported onto the cell surface of human spleen fibroblasts as a complex with the IL-15R $\alpha$ chain (Figures 2(b) and 2(c)). The trans-presentation of IL15 to bystander haematopoietic progenitors commits these cells to the NK differentiation pathway [85]. Similar results have been reported in murine bone marrow DC, where IL$15 \mathrm{R} \alpha / \mathrm{IL}-15$ cell membrane complexes activate NK cells via trans-presentation [86]. The study of in vivo models further supported the role of trans-presentation in peripheral NK cell activation and survival. Indeed, adoptive transfer of normal NK cells into mice lacking the IL-15R $\alpha$ results in the rapid disappearance of these cells. Conversely, IL-15R $\alpha$ deficient NK cells survive upon transfer in normal but not in IL-15R $\alpha$-deficient mice. Collectively these data show that IL-15R $\alpha$ expression on surrounding cells is crucial for the survival of peripheral NK cells, while IL-15R $\alpha$ expression on NK cells is not involved [87]. The finding that bone marrow progenitors from IL-15R $\alpha^{-1-}$ mice cultured with IL-7, stem cell factor (SCF) and FMS-like tyrosine kinase 3 ligand (FLT3L), followed by IL-15, differentiate into CD94/NKG2 ${ }^{+}$ NK cells, which lacked Ly49 expression, suggest that IL$15 \mathrm{R} \alpha$ on NK cell precursors is not required for NK cell development but is required for their Ly-49 expression [88].
IL-15 and IL-15R $\alpha$ have a broad tissue distribution, although their expression is not always coincident, raising the question about the cell type(s) involved in trans-presentation. IL-15 trans-presented by DC has been shown to activate NK cells both in vitro and in vivo [89]. In addition, a study suggested that both hematopoietic cells, such as DC and macrophages and nonhematopoietic cells, including stromal cells and epithelial cells are involved in transpresentation of IL-15 to human NK cells [90]. Moreover, mice lacking IL-15R $\alpha$ on macrophages, DCs, or on both, exhibit equivalent defects in NK cell homeostasis and activation, whereas only the expression on macrophages was important for the development of memory $\mathrm{CD}^{+} \mathrm{T}$ cell responses [89].

Besides the relevance of cell-bound IL-15R $\alpha$ in IL-15 trans-presentation, it has been hypothesized that IL-15R $\alpha$ may also act as a cis-presenting molecule $[83,91]$. In this model, the membrane IL-15R $\alpha /$ IL- 15 complex presents IL15 to neighbour IL-2R $\beta / \gamma_{c}$ complexes on the same cell (Figure $2(\mathrm{~d})$ ). In this context, previous data showed that human $\mathrm{CD}^{+}$or $\mathrm{CD}^{-}$neoplastic lymphoid cells from lymphoproliferative disorder of large granular lymphocytes (LDGL) express surface bound IL-15 [92]. As these cells express IL-15R $\alpha$ and proliferate to exogenous IL-15 stimulation, it is possible that they may bind IL-15 in vivo and store it on the cell membrane, thus allowing sustained stimulatory effects of endogenous IL-15 through cis-presentation. Nonetheless, the possible source of the in vivo bound IL-15 remains to be determined. The fact that IL-15 may not only 
support neoplastic NK cell proliferation but may also play a role in the pathogenesis of LDGL was also suggested by the observation of spontaneous LDGL-like leukemias occurring in mice with transgenic overexpression of IL-15 [93].

In addition to trans- or cis-presentation of IL-15 by IL$15 \mathrm{R} \alpha$, other forms of membrane-bound IL-15, independent from IL-15R $\alpha$, have been described. One of these IL-15 forms has been identified on human monocytes and may behave not only as a ligand but also as a signaling molecule. Thus, membrane-bound IL-15 may produce a reverse signaling that results in cellular adhesion and production of inflammatory cytokines [94]. Also, human haematopoietic progenitors derived from peripheral blood, but not from other sources, express an IL-15R $\alpha$-independent membranebound IL-15, which mediates reciprocal intercellular signals. This reciprocal trans-presentation induces the in vitro generation of a novel subset of mature noncytolytic NK cells (NKireg) that display regulatory functions and express the immunosuppressive molecule HLA-G. Remarkably, a small subset of $\mathrm{NKp} 46^{+} \mathrm{HLA}-\mathrm{G}^{+} \mathrm{IL}-10^{+}$is detected within freshly isolated decidual $\mathrm{NK}$ cells, suggesting that these cells could represent an in vivo counterpart of the in vitro-generated NKireg cells [95]. In addition, these NKireg precursors maintain along their differentiation process in vitro the expression of a membrane-IL-15 able to deliver a bidirectional signal. Indeed, the soluble IL- $15 \mathrm{R} \alpha$ chain, upon binding with membrane-IL-15, triggers a reverse signal leading to the appearance of an adherent subset with DC morphology. These cells may represent a terminally differentiated population, since they do not proliferate, display both specific NK (NKp46) and myeloid dendritic (CD1a and BDCA1) markers as well as cytokine production and functions, illustrating another possible chapter of the NK/DC functional interplay [96]. Nonetheless, the in vivo significance of these cells has not yet been explored.

Recent evidences also indicate that soluble forms of IL15 receptors can be generated by either alternative splicing or by in vivo cleavage of surface IL-15R $\alpha$ through metalloproteinase-driven mechanisms [97, 98]. Such natural soluble forms of IL-15R $\alpha$ corresponding to the extracellular domain behave either as a high-affinity IL-15 antagonists (Figure 2(f)) or as superagonist, depending on the isoform involved. Indeed, soluble IL-15R $\alpha \Delta 3$ isoform bound to recombinant IL-15 generates a soluble complex, "hyper-IL15 ", displaying a 100-fold higher biological activity on IL$2 \mathrm{R} \beta / \gamma_{c}{ }^{+}$target cells than that exerted by the soluble cytokine [85]. Moreover, a recombinant, soluble sushi domain of IL$15 \mathrm{R} \alpha$, capable to bind IL-15 with high affinity, is a potent IL-15 agonist and enhances the binding and the biological effects of IL- 15 mediated through the IL- $2 \beta / \gamma$ heterodimer (Figure 2(e)). Nonetheless, the possible in vivo sources of similar "hyper-IL-15" forms and their potential role in the innate and adaptive immune response remains to be determined. In addition, fusion proteins consisting of IL-15 and IL-15R $\alpha$-sushi domain linked by a flexible aminoacid sequence (RLI) are even more potent stimulators of NK and $\mathrm{T}$ cells [99]. The use of RLI or of soluble IL-15 on a T cell line expressing both IL-15R $\alpha /$ IL- $2 \mathrm{R} \beta / \gamma_{c}$ trimeric and IL$2 \mathrm{R} \beta / \gamma_{c}$ dimeric complexes allowed to study the dynamics of cis-presentation (by IL-15) or trans-presentation (by RLI). IL-15 cis-presentation induced fast and transient activation, while trans-presentation mediated slower and more persistent responses [100].

\section{Role of Cytokines in NK "Memory-Like" Responses}

In specific immunity, the expansion of antigen-specific memory cells and persistent antibody production in response to pathogen's antigen challenge provide enhanced protection against the same pathogen upon a subsequent exposure. By contrast, NK cells are generally thought to be "naturally active" cells, which constitutively display effector functions against infected or transformed cells [101] and are incapable of adapting their responsiveness and of maintaining a memory of a first pathogen encounter in subsequent challenges. However, it is well known that freshly isolated NK cells show low effector functions in terms of cytolytic activity and cytokine production when incubated in vitro with tumor target cells. Several evidences indicate that NK cells can modify their behavior in response to environmental stimuli and can even show memory-like responses in mouse models [102, 103]. For example, recombinase activation gene $(\mathrm{RAG})^{-/-}$mice (lacking both $\mathrm{T}$ and $\mathrm{B}$ cells) but not $\gamma_{c}$-deficient mice (lacking also NK cells) can develop delayed-type hypersensitivity (DTH) reactions to hapten. This response was specifically mediated by a subset of liver NK cells expressing Ly49C (an inhibitory receptor for self MHC molecules). In addition, NK cells from sensitized mice develop a specific memory-like function, since their adoptive transfer into naive mice can mediate DTH to the same hapten [104].

Besides this type of memory, which appears to be linked to expression of a specific type of receptor, NK cells may change their way of responding to stimuli following their exposure to specific cytokines [105]. Thus, NK cells from $\mathrm{RAG}^{-/-}$mice, activated for short-term with a cytokine cocktail consisting of IL-12, IL-18, and IL-15, produce high levels of IFN- $\gamma$ in vitro. Upon subsequent transfer into naïve hosts, these cells can be detected up to three weeks later when they are returned similar to resting NK cells, as they do not display constitutive production of IFN- $\gamma$ nor enhanced lytic properties. However, they produce significantly more IFN$\gamma$ than naive cells when restimulated. These data suggest that NK cells retain memory of prior cytokine activation. In addition, this memory-like function appeared as an inheritable characteristic, as cytokine-activated NK cells proliferated once injected in mice [105].

As already mentioned, DC can interact with NK cells and activate them via trans-presented IL-15 in vitro [86]. Subsequent findings in a mouse model indicate that similar to T cells, NK cells need to be primed by contact with DC to achieve a full ability to respond to pathogen in vivo and this priming is mediated by IL-15 [106]. Upon engagement of Toll-like receptor by pathogen ligands in the periphery, NK cells migrate into regional lymph nodes where their interact with DCs. NK cell priming required IFN-mediated activation 
of CD11c $\mathrm{c}^{+} \mathrm{DCs}$, which subsequently trans-present IL-15 to NK cells. Thus priming of NK cells results in arming, as IL15 can confer full cytolytic properties to NK cells [60]. NK cells become then effector cells and migrate the periphery, where they can efficiently respond to pathogens. Priming and arming is a short-term response finalized to effector functions needed to eliminate pathogens. However, it has been proposed that upon priming and arming NK cells can further develop into memory-like NK cells, which do not produce cytokines or display lytic properties but maintain the capacity to respond to a subsequent pathogen challenge in a more vigorous way than naïve NK cells [102].

Thus, several evidences suggest that NK cells are capable to mediate memory-like responses in different murine models, although the relevance of such responses in humans is still to be defined.

\section{Role of IL-7 in NK Cell Subset Development}

In addition to IL-15, which is strictly required for the generation of all NK cells $[21,28]$, other cytokines have been involved in the development of specific NK cell subsets in different organs. In fact, it is clear that NK cells derive from $\mathrm{CD}_{3} 4^{+}$hematopoietic progenitor cells originating in the bone marrow. However, early NK precursors can migrate to different organs, where they differentiate towards mature NK cells. Thus, the development of NK cells takes place not only in the bone marrow, but also in the thymus $[107,108]$, in secondary lymphoid organs [109] and in mucosae-associated lymphoid tissue in the gut in mice and humans [23, 110112]. Although most mature circulating NK cells do not express IL-7R $\alpha$, experimental evidences have been provided that thymic murine NK1.1 ${ }^{+}$cells express IL-7R $\alpha$ and that IL-7 is required for the homeostasis of these thymic NK cells [108]. Indeed, differently from classical NK cells, the development of thymic-derived NK cells is dependent upon IL-7 and GATA-3 transcription factor [108]. This peculiar subset is characterized by low cytotoxic activity but high cytokine secretion potential.

A subset of $\mathrm{CD} 56^{+} \mathrm{NKp} 44^{+}$cells has been identified in human tonsils, and mucosae-associated lymphoid tissues of the gut. Since these cells secrete IL-22 in response to IL23, they were termed "NK-22" cells [112]. Similar to Th17 cells, NK-22 cells express the transcription factors retinoicacid-related orphan receptor ROR $\gamma \mathrm{t}$ and aryl hydrocarbon receptor but do not produce IL-17. IL-7 supports the NK22 cell survival and maintains the ability to secrete IL-22 in response to IL-23 stimulation. In addition, the combination of IL-7 with IL- $1 \beta$ or IL-2 also mediates NK-22 proliferation, indicating a synergistic effect of IL-7 with these cytokines [22]. The use of IL-1 $\beta$ and/or IL-2 altered the cytokine profile of NK22 cells, suggesting their functional plasticity. Indeed, IL- $1 \beta$ induced constitutive IL-22 secretion, while IL2 reduced secretion of IL-22 and induced production of IFN$\gamma$.

A murine equivalent of NK-22 cells has been identified in gut-associated lymphoid tissues [20] on the basis of their expression of the natural cytotoxicity receptor
(NCR) NKp46, a specific marker of NK cells from several species [113]. This subset was phenotyically characterized as NKp $46^{+}$IL-7R $\alpha^{+}$ROR $\gamma \mathrm{t}^{+}$and depends for its development on IL-7, ROR $\gamma \mathrm{t}$, and intestinal microbial flora $[20,110]$. Different from classical NK cells, the development of these mucosal-associated NK cells does not require on IL-15 or IL-2R $\beta$. Altogether, these data suggest that IL-22-producing $\mathrm{NKp} 46^{+}$IL-7R $\alpha^{+} \mathrm{ROR} \gamma \mathrm{t}^{+}$cells and classical NK cells develop through different pathways under the control of different cytokines [20].

Since intestinal mouse $\mathrm{CD}^{-} \mathrm{NKp} 46^{+}$and human NK22 cells have some features of immature NK cells, they may possibly represent NK cell precursors that develop locally into specialized NK cell subsets, under the influence of a specific cytokine milieu and microbial product stimulation $[23,111]$. In addition, a population of IL-22-producing immature NK cells showing a CD34- IL-7R $\alpha^{+} \mathrm{CD} 161^{+} \mathrm{CD} 9^{-}$ surface phenotype, which do not produce IFN- $\gamma$ and lack of cytolytic activity, has been described in human secondary lymphoid organs [114].

A recent report showed that rare human $\mathrm{CD}_{3} 4^{+}$hematopoietic progenitors develop into NK cells in vitro in the presence of cytokines, such as IL-7, IL-15, SCF, and FLT3L. Moreover, the addition of hydrocortisone and stromal cells enhanced the frequency of progenitor cells that could develop into killer cell Ig-like receptor (KIR) ${ }^{+} \mathrm{NK}$ cells [115]. These data suggest that NK cells can be derived from precursor cells committed to the myeloid lineage. This latter point is also supported by the existence of human $\mathrm{CD} 14^{+}$ myeloid-like cells within cord blood behaving as a novel progenitor for NK cells. Indeed, this $\mathrm{CD}^{+} 4^{+}$myeloid-like subset can be redirected into NK differentiation in the presence of IL-15 and then generates mature functional NK cells [116].

$\mathrm{CD}^{+} 4^{+}$hematopoietic precursors in human decidua were recently found to express IL-2R $\beta, \mathrm{IL}-7 \mathrm{R} \alpha$, and mRNA for E4BP4 and ID2 transcription factors involved in NK cell development [117]. These data suggested that decidual $\mathrm{CD} 34^{+}$cells are precursors committed to the NK cell lineage. In fact, these cells differentiate into functional IL-8- and IL-22-producing $\mathrm{CD} 56^{\text {bright }} \mathrm{CD} 16^{-} \mathrm{KIR}^{+/-} \mathrm{NK}$ cells in the presence of growth factors (including IL-15 and IL-7) or upon coculture with decidual stromal cells.

\section{IL-21 as a Regulator of NK Cell Responses}

IL-21 is produced by $\mathrm{CD}^{+} \mathrm{T}$ cells in response to antigen presentation by DC during the adaptive immune response. At this stage, murine NK cells have been already activated by IL-12 and IL-15 produced by DC and then IL- 21 can further support their proliferation and induce their functional maturation into potent effector cells with large granular lymphocyte morphology [118]. Thus, IL-21 upregulates the expression of CD16, the Fc- $\gamma$ RIII required for in antibodydependent cellular cytotoxicity (ADCC), costimulates the secretion of IFN- $\gamma$, and upregulates the expression of granzyme and perforins. Similarly, IL-21 potentiates human NK cell ADCC activity and their ability to secrete cytokines 
in response to antibody-coated tumor target cells [119]. IL21 is also capable to boost NK-mediated ADCC in NK cells with defective cytotoxic properties, such as those of headand-neck cancer patients [120]. However, different from IL-2 and IL-15, IL-21 alone does not mediate NK cell proliferation though at low concentrations, it costimulates the mitogenic effect of IL-2 or IL-15 [121, 122]. Although it is clear that IL-21 is an important regulator of NK cell functions [30], IL21 may display positive and negative effects on NK cells, in relationship to their activation/maturation stage and species of origin. In fact, remarkable differences in IL-21 activity have been observed in mouse and human NK cells. Although IL-21 costimulates several functional properties of IL-15activated murine NK cells, such as IFN- $\gamma$ production and cytotoxicity, it does not support their survival. Instead, IL21 , at high concentrations, limits the proliferation of NK cells mediated by IL-15 and promotes an apoptotic program. Thus, it has been proposed that IL-21 mediates the transition of an early innate towards an adaptive response in the mouse, through the elimination of terminally differentiated NK cells and the induction of cytotoxic T lymphocyte (CTL) memory responses [123]. Differently, IL-21 alone stimulates the cytolytic activity of freshly isolated, peripheral human NK cells and the combination of low concentrations IL-21 plus IL- 15 costimulates the expansion of $\mathrm{CD} 56^{+} \mathrm{CD} 16^{+} \mathrm{NK}$ cells, which develop strong effector functions [121]. Possible explanations for these discrepancies may relate not only to species differences but also to the concentrations of IL-21 and IL-15 that were used in the different experiments or on the timing and activation state of NK cells.

NKG2D is an important activation receptor on mouse and human NK cells and triggers cytotoxicity upon engagement with ligands, such as antibodies or cell surface ligands. These effects are mediated through DNAX-activating protein of $10 \mathrm{kDa}$ (DAP10). Data in a mouse tumor model showed that IL-21 is able to enhance tumor rejection through an NKG2D-dependent mechanism [124] as NKG2D-blocking inhibited the antitumor activity and cytotoxicity of IL-21 activated NK cells. On the opposite, treatment of human $\mathrm{NK}$ and $\mathrm{CD} 8^{+} \mathrm{T}$ cells with IL-21 in combination with IL-2 reduces the cell surface expression of NKG2D and its ability to trigger cytotoxicity, relative to cells treated with IL-2 alone [125]. IL-21-induced downregulation of NKG2D is related to inhibition of DAP10 gene transcription. However, IL-21 induced the expression of the NK activation receptors NKp30 and 2B4, suggesting that IL-21 modulates human NK cell functions and their target specificity by altering the expression levels of different activation/costimulatory receptors.

IL-21 also induced an accelerated development of NK cells from human cord blood $\mathrm{CD} 34^{+}$haematopoietic progenitor cells, in concert with IL-7, IL-15, and SCF. Indeed IL-21 costimulates the expression of NKp46 and NKp30 triggering receptors, CD94/NKG2A inhibitory receptor, KIRs, CD2, and CD16, typical of mature NK cells and the acquisition of cytotoxic activity [126]. In addition, also rare CD34- lineage $^{-}$cells cultured with Flt3-L, SCF proliferated in response to IL-15 and IL-21 and acquired a $\mathrm{KIR}^{-} \mathrm{CD} 56^{+} \mathrm{CD} 16^{-/+}$lymphoid phenotype, consistent with pseudomature NK cells. These cells secreted IFN- $\gamma$, GM-CSF and MIP- $1 \alpha$, and displayed cell surface CD107a upon contact with NK-sensitive targets [127]. Thus IL-21 may possibly have a role in the development of NK cells although the study of IL-21 KO mice indicated that IL-21 is not strictly necessary for the differentiation of NK cells from progenitors [56].

\section{Perspectives for Cancer Immunotherapy}

IL-2 represents a milestone in the history of the immunotherapy of cancer and is still clinically used for the treatment of advanced melanoma and renal carcinoma. The induction of some long-lasting remissions in metastatic patients treated with recombinant (r)IL-2 alone or in combination with LAK cells provided an important proof of principle that activation of the immune system may result in tumor rejection even in patients with bulky disease [128]. However, these effects were observed in a minor subset of patients and the treatment showed a remarkable toxicity, predominantly related to "vascular leak syndrome" [129] and adverse effects on the heart [128]. The availability of novel recombinant cytokines may offer new possibilities for cancer immunotherapy [130, 131].

The functional properties of IL-15 have suggested the use for this cytokine in tumor immunotherapy [12]. It is hoped that IL-15 may display lower toxic effects than IL-2 and provide similar immune-enhancing effects on tumorreactive $\mathrm{T}$ and NK cells. In early experiments, tumor cells transduced with a modified IL-15 cDNA, allowing enhanced IL-15 secretion, showed reduced tumorigenic potential in immunodeficient [132] or in syngeneic mice [133], through the recruitment of NK cells and/or CTLs. In addition, IL15-transduced tumor cells, administered as vaccine, reduced the incidence of experimental metastases in syngeneic mice. Administration of rIL-15 has also been shown to display antitumor activity in murine tumor models with a lower toxicity than rIL-2 [134]. Finally, plasmid gene transfer of IL15 trough an hydrodynamic method increases the number and function of NK and IFN-producing killer DC cells in mice [135].

In a preclinical study, human rIL-15, administered intravenously daily for 12 days to rhesus macaques, showed both short- and long-lasting effects on lymphoid cell homeostasis. A transient lymphopenia preceded a clearcut increase in $\mathrm{NK}$ and memory $\mathrm{CD} 8^{+} \mathrm{T}$ cells in the peripheral blood. An inverted CD4/CD8 T-cell ratio was observed as result of $\mathrm{CD}^{+} \mathrm{T}$ cell expansion. By day 48, homeostasis appears restored throughout the body, with the exception of the maintenance of an inverted CD4/CD8 ratio in lymph nodes [136]. A phase I study of intravenous rIL-15 in adults with refractory metastatic melanoma and renal cancer has been recently started and is currently recruiting participants. The objectives of this study are the evaluation of the safety and efficacy of rIL-15 and to examine how the body processes the infused cytokine [NCT01021059].

Since the scaling up of IL-15 production for clinical purposes has been technically difficult, the possible usage of hyper IL-15 in clinical settings of cancer immunotherapy can be envisaged. The potential advantages are that hyper-IL-15 
would act in lower doses than IL-15, as it is a more potent activator of the immune system than IL-15 on a molar basis. Interestingly, the potential development of hyper-IL-15 in NK-based immunotherapy is also illustrated by data from Kroemer et al. [137] in a skin transplant in $\mathrm{Rag}^{-/-}$mice. Resting NK cells did not reject skin allografts, while hyperIL-15-stimulated NK cells mediated acute skin allograft rejection in the absence of $\mathrm{T}$ and $\mathrm{B}$ cells.

The transfer of NK cells is an emerging strategy for cancer immunotherapy, particularly in haematologic neoplasia. A pivotal role in the antileukemic effects of allogeneic NK cell transfer is played by KIRs, which are inhibitory receptors for HLA class I molecules [138]. The engagement of a KIR expressed on the NK cell surface by the appropriate HLA class I allele on a target cell produces an inhibitory signal to the NK cell activation resulting in target cell protection. In $\mathrm{T}$ cell-depleted haploidentical hematopoietic stem cell transplantation (haplo-HSCT) donor NK cells may express $\operatorname{KIR}(\mathrm{s})$ that do not recognize the HLA-class I alleles present on recipient's cells. In this "KIR-mismatch" setting, these "alloreactive" NK cells efficiently lyse leukemic cells and generate a strong graft versus leukemia effect, which contributes in eradicating residual disease. In addition, alloreactive NK cells eliminate residual host dendritic cells, thus preventing graft-versus-host disease [138].

Because NK cells are a fraction of peripheral blood mononuclear cells the development of methods to produce large numbers of functional NK cells could be useful to optimize NK-based therapies. Coculture of NK cells with K562 leukemia cells, genetically modified to express membranebound IL-15 and 41BBL, allowed a 20-fold expansion of $\mathrm{CD}_{56}{ }^{+} \mathrm{CD}^{-} \mathrm{NK}$ cells from peripheral blood but induced no proliferation of $\mathrm{T}$ cells. The expanded NK cells were potent effectors against acute myeloid leukemia cells (AML) in vitro and eradicated AML in xenograft models in immunodeficient mice. This method provide a new platform for expanding activated NK cells for cell therapy of cancer [139].

In view of its immune-enhancing functions, also IL21 has been considered as a good candidate for cancer immunotherapy. In addition, IL-21, differently from IL-2 is unable to mediate the proliferation of activated $\mathrm{CD}^{+}{ }^{+} \mathrm{CD} 25^{+} \mathrm{Foxp}^{+}{ }^{+}$Treg cells in vitro [140] although Treg cells express IL-21R gene. Nonetheless also IL-21 has shown immune regulatory functions related to the induction of IL-10 production, which inhibits the immune response by acting at several levels [141]. Although this may represent a potential drawback, it is almost likely that each immune enhancing cytokine possess its own negative regulatory mechanisms, to prevent exaggerated responses and autoimmune reactivity.

Several studies in murine tumor models has shown that IL-21 is endowed with antitumor properties [142, 143], which can be mediated by NK, T, or B cell-dependent responses, in relationship to the experimental model considered.

Different types of tumor cells, genetically modified to produce IL-21, form small tumors when injected into syngeneic mice and are then eventually rejected by an IL-21driven immune reaction, which is followed by immunity to tumor antigens [144]. In addition, human pancreatic cancer cells transduced with murine IL-21 gene are rejected when xenografted in immune-deficient mice through activation of NK cells [145]. In a syngeneic model of mammary adenocarcinoma, tumor-released IL-21 induced the local recruitment of both $\mathrm{CD}^{+}$and $\mathrm{NK}$ cells and the production of IFN- $\gamma$ and of IFN- $\gamma$-dependent CXC chemokines, which mediated local antiangiogenic effects [144]. IL-21transduced tumor cells were also effective when used as a vaccine to treat metastatic tumors $[140,146]$. However, in the mammary adenocarcinoma model, the therapeutic effect was partial and could be synergistically enhanced by targeting $\mathrm{CD} 4^{+} \mathrm{CD} 25^{+}$Treg cells by an anti-CD $25 \mathrm{mAb}$ [140]. Thus, Treg cells appeared to limit not only CTLbut also NK-mediated responses by tumor-released IL-21. The antitumor effects of IL-21 therapy did not require Th cells, suggesting that IL-21 may bypass the requirement of Th cells for the induction of CTL and NK responses. In a neuroblastoma syngeneic model the efficacy of IL-21-based immunotherapy was even enhanced by transient $\mathrm{CD} 4^{+} \mathrm{T}$ cell depletion, which also resulted in the elimination of $\mathrm{CD} 4^{+}$ Treg cells [147].

Another approach has been the direct gene transfer of IL21 in vivo through a plasmid-based hydrodynamic system, which results in sustained IL-21 levels and NK-dependent antitumor effects in syngeneic tumor models [148]. The coinjection of IL-15- and IL-21-encoding plasmids in mice bearing lymphoma produced cooperative effects of tumor rejection [149]. Also, the injection of plasmids encoding for an IL-21/IgFc chimeric protein mediated antitumor effects in melanoma-bearing syngeneic mice, through the induction of an NK-mediated response [150]. Other studies combined IL21 protein administration with antibody treatments. In view of the ability of IL-21 to enhance ADCC activity by NK cells, rIL-21 has been combined with an anti-Her2/neu antibody to treat mice bearing Her2/neu ${ }^{+}$tumors. This combination showed a synergistic antitumor effect through an IFN- $\gamma$ dependent mechanism [119].

Altogether preclinical studies led to the design of clinical trials in cancer patients. Several clinical studies of rIL-21 monotherapy or combining IL-21 with other drugs are now ongoing in different type of cancers. Phase I studies in melanoma and renal cancer have been already concluded and showed that IL-21 has an acceptable toxicity profile and does not induce vascular-leak syndrome by repeated iv infusion $[151,152]$ or subcutaneous administration [153]. IL-21 induced increased levels of soluble CD25 and upregulated IFN- $\gamma$, perforin, and granzyme B expression in circulating $\mathrm{CD}^{+} \mathrm{T}$ cells and NK cells, indicating cytotoxic lymphocyte activation. By i.v., IL-21 induced a dose-dependent decrease in circulating NK and T cells, followed by a return to baseline in resting periods. Objective responses and disease stabilizations were observed and were also confirmed in an initial phase II clinical study [154], which also suggested an increase in progression-free survival.

Besides immune-enhancing activities, IL-21 mediates apoptosis of specific B cell malignancies such as chronic lymphocytic leukemia $[34,35]$ and follicular [37] or diffuse large $\mathrm{B}$ cell lymphoma $[36]$. $\mathrm{CD} 4^{+} \mathrm{CD} 25^{+}$regulatory $\mathrm{T}$ cells are 
expanded in solid and hematological malignancies including CLL and the use of IL-21 instead of IL- 2 may contribute to limit this expansion [155]. For this reason and for the ability of IL-21 to enhance ADCC activity by NK cells, a phase I trial of rIL-21 combined with the anti-CD20 mAb rituximab has been designed in chemotherapy refractory/relapsed nonHodgkin's lymphoma. Acceptable toxicity, several objective responses, and disease stabilizations were reported in a preliminary analysis of data [156]. Overall data from early clinical trials indicate that IL-21 warrants further testing, particularly in multimodality therapy regimens for cancer.

IL-21 also plays a role in controlling chronic viral infections and its serum levels were reduced in HIV-infected persons, which display defective NK activity. Two recent reports indicated that IL-21 enhanced viability, HIV-specific ADCC, IFN- $\gamma$ secretion, and cytotoxic functions of NK cells from HIV-infected persons [157, 158]. In addition, the IL21-activated NK cells inhibit viral replication in cocultured $\mathrm{CD}^{+} \mathrm{T}$ cells. These data suggest that that IL-21 could represent a potential tool for immunotherapy or as adjuvant for vaccines in HIV-infected patients.

The systemic administration of cytokines at high doses frequently results in toxicities, and the amount of cytokine effectively delivered at the tumor site is generally low. Tumor cells genetically modified to secrete cytokines may elicit potent immune responses upon injection in syngeneic mice, without systemic effects, due to a high local concentration of cytokine. Although cytokine gene transfer procedures have shown some promising effects in easily accessible tumors (such as subcutaneous melanoma metastases) [159], it cannot be easily applied in case of systemic metastases. Another possibility to reduce systemic toxicity and reach high cytokine concentrations at the tumor site is based on the targeted delivery of cytokines, through the generation of fusion proteins formed by a recombinant antibody linked to a cytokine. These antibody/cytokine chimeras, defined as immunocytokines, have shown promising results in animal models [160]. An example of such immunocytokines is L19IL-2 [161], which was obtained by chimerization of IL-2 with a single-chain human antibody specific for an oncofetal fibronectin isoform of the tumor extracellular matrix. L19IL-2 was capable to accumulate at sites of neoangiogenesis in tumors, to determine the recruitment of $\mathrm{T}$ and $\mathrm{NK}$ and to induce tumor regression in both syngeneic and nude mice. Therefore, L19-IL-2 has entered several clinical trials in different types of tumors and a phase I study was recently concluded [NCT01058538] [162]. This study showed that L19-IL-2 can be safely and repeatedly administered in advanced solid tumours and preliminary evaluation suggests clinical activity in patients with metastatic renal carcinoma.

In a murine neuroblastoma model, the therapeutic effect of an immunocytokine consisting of an anti-GD2 antibody linked to IL-2 was dependent on NK cells [163]. In addition, most human neuroblastomas express low levels of HLA class I [164] and express ligands for NCR activating receptors, thus representing potential targets for NK-based therapies [165]. A phase II trial of the humanized anti-GD2 monoclonal antibody linked to human IL-2 (hu14.18-IL2) was recently performed on relapsed/refractory neuroblastoma patients.
To explore the role of NK cells in this treatment patients were genotyped for KIR, HLA, and FcR alleles. The presence of a KIR/KIR-ligand mismatch was signficantly associated with response/improvement to immunocytokine, and there was a trend towards a higher response rate in patients with the Fc $\gamma$ R2A 131-H/H genotype than other genotypes. These findings are strongly suggestive for a role of NK cells in clinical responses to hu14.18-IL2 cytokine treatment in relapsed/refractory neuroblastoma patients [166].

\section{Conclusions}

In conclusion, several evidences indicate that IL-2, IL-7, IL-15, and IL-21 play important roles in NK cell biology and that, in spite of some redundancy, each cytokine has clearly distinct functions. In addition, they may differentially act on subset of NK cells, whose phenotypic and functional heterogeneity is now well established. Moreover, these cytokines allow to manipulate and expand NK cells in vitro to generate populations with increased effector functions or to directly boost NK cell activity in vivo. Thus, these cytokines may represent potentially relevant tools for NK-based immunotherapy strategies in diseases such as leukemias, solid tumors, and AIDS. In this context, the development of novel strategies of cytokine targeted delivery or the use of synergistic combinations with antibodies or of different cytokines may offer the possibility to maximize their therapeutic potential.

\section{Acknowledgment}

The author's work has been supported by grants awarded from Italian Ministry of Health Ordinary Project and Strategical Project, Compagnia San Paolo, and AIRC (Italian Association for Cancer Research).

\section{References}

[1] Y. Rochman, R. Spolski, and W. J. Leonard, "New insights into the regulation of T cells by $\gamma$ family cytokines," Nature Reviews Immunology, vol. 9, no. 7, pp. 480-490, 2009.

[2] T. Takeshita, H. Asao, K. Ohtani et al., "Cloning of the $\gamma$ chain of the human IL-2 receptor," Science, vol. 257, no. 5068, pp. 379-382, 1992.

[3] M. Kondo, T. Takeshita, N. Ishii et al., "Sharing of the interleukin-2 (IL-2) receptor $\gamma$ chain between receptors for IL-2 and IL-4," Science, vol. 262, no. 5141, pp. 1874-1877, 1993.

[4] R. N. Bamford, A. J. Grant, J. D. Burton et al., "The interleukin (IL) 2 receptor $\beta$ chain is shared by IL-2 and a cytokine, provisionally designated IL-T, that stimulates Tcell proliferation and the induction of lymphokine-activated killer cells," Proceedings of the National Academy of Sciences of the United States of America, vol. 91, no. 11, pp. 4940-4944, 1994.

[5] K. H. Grabstein, J. Eisenman, K. Shanebeck et al., "Cloning of a $\mathrm{T}$ cell growth factor that interacts with the $\beta$ chain of the interleukin-2 receptor," Science, vol. 264, no. 5161, pp. 965968, 1994. 
[6] K. Ghoreschi, A. Laurence, and J. J. O’Shea, "Janus kinases in immune cell signaling," Immunological Reviews, vol. 228, no. 1, pp. 273-287, 2009.

[7] D. De Totero, R. Meazza, M. Capaia et al., "The opposite effects of IL-15 and IL-21 on CLL B cells correlate with differential activation of the JAK/STAT and ERK1/2 pathways," Blood, vol. 111, no. 2, pp. 517-524, 2008.

[8] J. J. OShea, M. Gadina, and R. D. Schreiber, "Cytokine signaling in 2002: new surprises in the Jak/Stat pathway," Cell, vol. 109, supplement 2, pp. S121-S131, 2002.

[9] P. E. Kovanen and W. J. Leonard, "Cytokines and immunodeficiency diseases: critical roles of the $\gamma$-dependent cytokines interleukins 2, 4, 7, 9, 15, and 21, and their signaling pathways," Immunological Reviews, vol. 202, pp. 67-83, 2004.

[10] T. Taniguchi, H. Matsui, and T. Fujita, "Structure and expression of a cloned cDNA for human interleukin-2," Nature, vol. 302, no. 5906, pp. 305-310, 1983.

[11] S. Gillis, M. M. Ferm, W. Ou, and K. A. Smith, "T cell growth factor: parameters of production and a quantitative microassay for activity," Journal of Immunology, vol. 120, no. 6, pp. 2027-2032, 1978.

[12] T. A. Waldmann, "The biology of interleukin-2 and interleukin-15: implications for cancer therapy and vaccine design," Nature Reviews Immunology, vol. 6, no. 8, pp. 595601, 2006.

[13] S. Romagnani, "Immunologic influences on allergy and the T1/T2 balance," Journal of Allergy and Clinical Immunology, vol. 113, no. 3, pp. 395-400, 2004.

[14] J. Brady, S. Carotta, R. P. L. Thong et al., "The interactions of multiple cytokines control NK cell maturation," Journal of Immunology, vol. 185, no. 11, pp. 6679-6688, 2010.

[15] F. Gays, K. Martin, R. Kenefeck, J. G. Aust, and C. G. Brooks, "Multiple cytokines regulate the NK gene complex-encoded receptor repertoire of mature NK cells and T cells," Journal of Immunology, vol. 175, no. 5, pp. 2938-2947, 2005.

[16] E. Marcenaro, M. Della Chiesa, F. Bellora et al., "IL-12 or IL4 prime human NK cells to mediate functionally divergent interactions with dendritic cells or tumors," Journal of Immunology, vol. 174, no. 7, pp. 3992-3998, 2005.

[17] A. Puel, S. F. Ziegler, R. H. Buckley, and W. J. Leonard, "Defective IL7R expression in TBNK severe combined immunodeficiency," Nature Genetics, vol. 20, no. 4, pp. 394-397, 1998.

[18] J. J. Peschon, P. J. Morrissey, K. H. Grabstein et al., "Early lymphocyte expansion is severely impaired in interleukin 7 receptor-deficient mice," Journal of Experimental Medicine, vol. 180, no. 5, pp. 1955-1960, 1994.

[19] R. G. J. Klein Wolterink, M. E. García-Ojeda, C. A. J. Vosshenrich, R. W. Hendriks, and J. P. Di Santo, "The intrathymic crossroads of T and NK cell differentiation," Immunological Reviews, vol. 238, no. 1, pp. 126-137, 2010.

[20] N. Satoh-Takayama, S. Lesjean-Pottier, P. Vieira et al., "IL7 and IL-15 independently program the differentiation of intestinal CD3-NKp46+ cell subsets from Id2-dependent precursors," Journal of Experimental Medicine, vol. 207, no. 2, pp. 273-280, 2010.

[21] C. A. J. Vosshenrich, T. Ranson, S. I. Samson et al., "Roles for common cytokine receptor $\gamma$-chain-dependent cytokines in the generation, differentiation, and maturation of NK cell precursors and peripheral NK cells in vivo," Journal of Immunology, vol. 174, no. 3, pp. 1213-1221, 2005.

[22] M. Cella, K. Otero, and M. Colonna, "Expansion of human NK-22 cells with IL-7, IL-2, and IL-1 $\beta$ reveals intrinsic functional plasticity," Proceedings of the National Academy of Sciences of the United States of America, vol. 107, no. 24, pp. 10961-10966, 2010.

[23] M. Colonna, "Interleukin-22-producing natural killer cells and lymphoid tissue inducer-like cells in mucosal immunity," Immunity, vol. 31, no. 1, pp. 15-23, 2009.

[24] P. Vacca, C. Vitale, E. Montaldo et al., "CD34+ hematopoietic precursors are present in human decidua and differentiate into natural killer cells upon interaction with stromal cells," Proceedings of the National Academy of Sciences of the United States of America, vol. 108, no. 6, pp. 2402-2407, 2011.

[25] R. J. Noelle and E. C. Nowak, "Cellular sources and immune functions of interleukin-9," Nature Reviews Immunology, vol. 10, no. 10, pp. 683-687, 2010.

[26] W. E. Carson, J. G. Giri, M. J. Lindemann et al., "Interleukin (IL) 15 is a novel cytokine that activates human natural killer cells via components of the IL-2 receptor," Journal of Experimental Medicine, vol. 180, no. 4, pp. 1395-1403, 1994.

[27] J. P. Lodolce, D. L. Boone, S. Chai et al., "IL-15 receptor maintains lymphoid homeostasis by supporting lymphocyte homing and proliferation," Immunity, vol. 9, no. 5, pp. 669676, 1998.

[28] M. K. Kennedy, M. Glaccum, S. N. Brown et al., "Reversible defects in natural killer and memory CD8 T cell lineages in interleukin 15-deficient mice," Journal of Experimental Medicine, vol. 191, no. 5, pp. 771-780, 2000.

[29] W. E. Carson, T. A. Fehniger, S. Haldar et al., "A potential role for interleukin-15 in the regulation of human natural killer cell survival," Journal of Clinical Investigation, vol. 99, no. 5, pp. 937-943, 1997.

[30] J. Parrish-Novak, S. R. Dillon, A. Nelson et al., "Interleukin 21 and its receptor are involved in NK cell expansion and regulation of lymphocyte function," Nature, vol. 408, no. 6808, pp. 57-63, 2000.

[31] K. Ozaki, K. Kikly, D. Michalovich, P. R. Young, and W. J. Leonard, "Cloning of a type I cytokine receptor most related to the IL-2 receptor $\beta$ chain," Proceedings of the National Academy of Sciences of the United States of America, vol. 97, no. 21, pp. 11439-11444, 2000.

[32] R. Spolski and W. J. Leonard, "Interleukin-21: basic biology and implications for cancer and autoimmunity," Annual Review of Immunology, vol. 26, pp. 57-79, 2008.

[33] D. Konforte, N. Simard, and C. J. Paige, "IL-21: an executor of B cell fate," Journal of Immunology, vol. 182, no. 4, pp. 17811787, 2009.

[34] D. De Totero, R. Meazza, S. Zupo et al., "Interleukin-21 receptor (IL-21R) is up-regulated by CD40 triggering and mediates proapoptotic signals in chronic lymphocytic leukemia B cells," Blood, vol. 107, no. 9, pp. 3708-3715, 2006.

[35] A. Gowda, J. Roda, S. R. A. Hussain et al., "IL-21 mediates apoptosis through up-regulation of the $\mathrm{BH} 3$ family member BIM and enhances both direct and antibody-dependent cellular cytotoxicity in primary chronic lymphocytic leukemia cells in vitro," Blood, vol. 111, no. 9, pp. 4723-4730, 2008.

[36] K. A. Sarosiek, R. Malumbres, H. Nechushtan, A. J. Gentles, E. Avisar, and I. S. Lossos, "Novel IL-21 signaling pathway upregulates c-Myc and induces apoptosis of diffuse large B-cell lymphomas," Blood, vol. 115, no. 3, pp. 570-580, 2010.

[37] D. de Totero, M. Capaia, M. Fabbi et al., "Heterogeneous expression and function of IL-21R and susceptibility to IL-21-mediated apoptosis in follicular lymphoma cells," Experimental Hematology, vol. 38, no. 5, pp. 373-383, 2010.

[38] M. Tsudo, C. K. Goldman, K. F. Bongiovanni et al., "The p75 peptide is the receptor for interleukin 2 expressed on large 
granular lymphocytes and is responsible for the interleukin 2 activation of these cells," Proceedings of the National Academy of Sciences of the United States of America, vol. 84, no. 15, pp. 5394-5398, 1987.

[39] E. A. Grimm, R. J. Robb, J. A. Roth et al., "Lymphokineactivated killer cell phenomenon. III. Evidence that IL-2 is sufficient for direct activation of peripheral blood lymphocytes into lymphokine-activated killer cells," Journal of Experimental Medicine, vol. 158, no. 4, pp. 1356-1361, 1983.

[40] S. Ferrini, S. Miescher, and M. R. Zocchi, "Phenotypic and functional characterization of recombinant interleukin 2 (rIL 2)-induced activated killer cells: analysis at the population and clonal levels," Journal of Immunology, vol. 138, no. 4, pp. 1297-1302, 1987.

[41] M. A. Caligiuri, A. Zmuidzinas, T. J. Manley, H. Levine, K. A. Smith, and J. Ritz, "Functional consequences of interleukin 2 receptor expression on resting human lymphocytes. Identification of a novel natural killer cell subset with high affinity receptors," Journal of Experimental Medicine, vol. 171, no. 5, pp. 1509-1526, 1990.

[42] A. Nagler, L. L. Lanier, and J. H. Phillips, "Constitutive expression of high affinity interleukin 2 receptors on human CD16 natural killer cells in vivo," Journal of Experimental Medicine, vol. 171, no. 5, pp. 1527-1533, 1990.

[43] M. Itoh, T. Takahashi, N. Sakaguchi et al., "Thymus and autoimmunity: production of CD25+CD4+ naturally anergic and suppressive $\mathrm{T}$ cells as a key function of the thymus in maintaining immunologic self-tolerance," Journal of Immunology, vol. 162, no. 9, pp. 5317-5326, 1999.

[44] T. R. Malek and I. Castro, "Interleukin-2 receptor signaling: at the interface between tolerance and immunity," Immunity, vol. 33, no. 2, pp. 153-165, 2010.

[45] R. Setoguchi, S. Hori, T. Takahashi, and S. Sakaguchi, "Homeostatic maintenance of natural Foxp3(+) CD25(+) $\mathrm{CD} 4(+)$ regulatory $\mathrm{T}$ cells by interleukin (IL)-2 and induction of autoimmune disease by IL-2 neutralization," Journal of Experimental Medicine, vol. 201, no. 5, pp. 723-735, 2005.

[46] J. D. Fontenot, J. P. Rasmussen, M. A. Gavin, and A. Y. Rudensky, "A function for interleukin 2 in Foxp3-expressing regulatory T cells," Nature Immunology, vol. 6, no. 11, pp. 1142-1151, 2005.

[47] Y. Refaeli, L. Van Parijs, C. A. London, J. Tschopp, and A. K. Abbas, "Biochemical mechanisms of IL-2-regulated Fasmediated T cell apoptosis," Immunity, vol. 8, no. 5, pp. 615623, 1998.

[48] B. Sadlack, J. Löhler, H. Schorle et al., "Generalized autoimmune disease in interleukin-2-deficient mice is triggered by an uncontrolled activation and proliferation of CD4+ T cells," European Journal of Immunology, vol. 25, no. 11, pp. 3053-3059, 1995.

[49] D. M. Willerford, J. Chen, J. A. Ferry, L. Davidson, A. Ma, and F. W. Alt, "Interleukin-2 receptor $\alpha$ chain regulates the size and content of the peripheral lymphoid compartment," Immunity, vol. 3, no. 4, pp. 521-530, 1995.

[50] H. Suzuki, G. S. Duncan, H. Takimoto, and T. W. Mak, "Abnormal development of intestinal intraepithelial lymphocytes and peripheral natural killer cells in mice lacking the IL-2 receptor $\beta$ chain," Journal of Experimental Medicine, vol. 185, no. 3, pp. 499-505, 1997.

[51] K. C. Gilmour, H. Fujii, T. Cranston, E. Graham Davies, C. Kinnon, and H. B. Gaspar, "Defective expression of the interleukin-2/interleukin-15 receptor $\beta$ subunit leads to a natural killer cell-deficient form of severe combined immunodeficiency," Blood, vol. 98, no. 3, pp. 877-879, 2001.
[52] M. Noguchi, H. Yi, H. M. Rosenblatt et al., "Interleukin-2 receptor gamma chain mutation results in X-linked severe combined immunodeficiency in humans," Cell, vol. 73, pp. 147-157, 1993.

[53] J. P. DiSanto, W. Müller, D. Guy-Grand, A. Fischer, and K. Rajewsky, "Lymphoid development in mice with a targeted deletion of the interleukin 2 receptor $\gamma$ chain," Proceedings of the National Academy of Sciences of the United States of America, vol. 92, no. 2, pp. 377-381, 1995.

[54] M. A. Cooper, J. E. Bush, T. A. Fehniger et al., "In vivo evidence for a dependence on interleukin 15 for survival of natural killer cells," Blood, vol. 100, no. 10, pp. 3633-3638, 2002.

[55] T. Ranson, C. A. J. Vosshenrich, E. Corcuff, O. Richard, W. Müller, and J. P. Di Santo, "IL-15 is an essential mediator of peripheral NK-cell homeostasis," Blood, vol. 101, no. 12, pp. 4887-4893, 2003.

[56] C. A. J. Vosshenrich, T. Ranson, S. I. Samson et al., "Roles for common cytokine receptor $\gamma$-chain-dependent cytokines in the generation, differentiation, and maturation of NK cell precursors and peripheral NK cells in vivo," Journal of Immunology, vol. 174, no. 3, pp. 1213-1221, 2005.

[57] D. M. Anderson, S. Kumaki, M. Ahdieh et al., "Functional characterization of the human interleukin-15 receptor $\alpha$ chain and close linkage of IL15RA and IL2RA genes," Journal of Biological Chemistry, vol. 270, no. 50, pp. 29862-29869, 1995.

[58] J. G. Giri, S. Kumaki, M. Ahdieh et al., "Identification and cloning of a novel IL-15 binding protein that is structurally related to the $\alpha$ chain of the IL-2 receptor," EMBO Journal, vol. 14, no. 15, pp. 3654-3663, 1995.

[59] A. M. Gamero, D. Ussery, D. S. Reintgen, C. A. Puleo, and J. Y. Djeu, "Interleukin 15 induction of lymphokineactivated killer cell function against autologous tumor cells in melanoma patient lymphocytes by a CD18-dependent, perforin-related mechanism," Cancer Research, vol. 55, no. 21, pp. 4988-4994, 1995.

[60] T. A. Fehniger, S. F. Cai, X. Cao et al., "Acquisition of murine NK cell cytotoxicity requires the translation of a pre-existing pool of granzyme B and perforin mRNAs," Immunity, vol. 26, no. 6, pp. 798-811, 2007.

[61] N. D. Huntington, H. Puthalakath, P. Gunn et al., "Interleukin 15-mediated survival of natural killer cells is determined by interactions among Bim, Noxa and Mcl-1," Nature Immunology, vol. 8, no. 8, pp. 856-863, 2007.

[62] L. Chiossone, C. Vitale, F. Cottalasso et al., "Molecular analysis of the methylprednisolone-mediated inhibition of NK-cell function: evidence for different susceptibility of IL2- versus IL-15-activated NK cells," Blood, vol. 109, no. 9, pp. 3767-3775, 2007.

[63] R. Meazza, S. Verdiani, R. Biassoni et al., "Identification of a novel interleukin-15 (IL-15) transcript isoform generated by alternative splicing in human small cell lung cancer cell lines," Oncogene, vol. 12, no. 10, pp. 2187-2192, 1996.

[64] R. Meazza, A. Gaggero, F. Neglia et al., "Expression of two interleukin-15 mRNA isoforms in human tumors does not correlate with secretion: role of different signal peptides," European Journal of Immunology, vol. 27, no. 5, pp. 10491054, 1997.

[65] A. Onu, T. Pohl, H. Krause, and S. Bulfone-Paus, "Regulation of IL-15 secretion via the leader peptide of two IL-15 isoforms," Journal of Immunology, vol. 158, no. 1, pp. 255-262, 1997. 
[66] A. Gaggero, B. Azzarone, C. Andrei et al., "Differential intracellular trafficking, secretion and endosomal localization of two IL-15 isoforms," European Journal of Immunology, vol. 29, no. 4, pp. 1265-1274, 1999.

[67] G. Kurys, Y. Tagaya, R. Bamford, J. A. Hanover, and T. A. Waldmann, "The long signal peptide isoform and its alternative processing direct the intracellular trafficking of interleukin-15," Journal of Biological Chemistry, vol. 275, no. 39, pp. 30653-30659, 2000.

[68] R. N. Bamford, A. P. DeFilippis, N. Azimi, G. Kurys, and T. A. Waldmann, “The 5' untranslated region, signal peptide, and the coding sequence of the carboxyl terminus of IL-15 participate in its multifaceted translational control," Journal of Immunology, vol. 160, no. 9, pp. 4418-4426, 1998.

[69] F. Colucci, M. A. Caligiuri, and J. P. Di Santo, "What does it take to make a natural killer?" Nature Reviews Immunology, vol. 3, no. 5, pp. 413-425, 2003.

[70] S. S. Farag and M. A. Caligiuri, "Human natural killer cell development and biology," Blood Reviews, vol. 20, no. 3, pp. 123-137, 2006.

[71] M. A. Caligiuri, "Human natural killer cells," Blood, vol. 112, no. 3, pp. 461-469, 2008.

[72] N. C. Fernandez, A. Lozier, C. Flament et al., "Dendritic cells directly trigger NK cell functions: cross-talk relevant in innate anti-tumor immune responses in vivo," Nature Medicine, vol. 5, no. 4, pp. 405-411, 1999.

[73] G. Ferlazzo, B. Morandi, A. D’Agostino et al., "The interaction between NK cells and dendritic cells in bacterial infections results in rapid induction of NK cell activation and in the lysis of uninfected dendritic cells," European Journal of Immunology, vol. 33, no. 2, pp. 306-313, 2003.

[74] T. A. Fehniger, M. H. Shah, M. J. Turner et al., "Differential cytokine and chemokine gene expression by human NK cells following activation with IL-18 or IL-15 in combination with IL-12: implications for the innate immune response," Journal of Immunology, vol. 162, no. 8, pp. 4511-4520, 1999.

[75] T. A. Fehniger, M. A. Cooper, G. J. Nuovo et al., "CD56bright natural killer cells are present in human lymph nodes and are activated by T cell-derived IL-2: a potential new link between adaptive and innate immunity," Blood, vol. 101, no. 8, pp. 3052-3057, 2003.

[76] G. Ferlazzo, M. Pack, D. Thomas et al., "Distinct roles of IL-12 and IL-15 in human natural killer cell activation by dendritic cells from secondary lymphoid organs," Proceedings of the National Academy of Sciences of the United States of America, vol. 101, no. 47, pp. 16606-16611, 2004.

[77] M. A. Cooper, T. A. Fehniger, S. C. Turner et al., "Human natural killer cells: a unique innate immunoregulatory role for the CD56(bright) subset," Blood, vol. 97, no. 10, pp. 31463151, 2001.

[78] A. De Maria, F. Bozzano, C. Cantoni, and L. Moretta, "Revisiting human natural killer cell subset function revealed cytolytic CD56dimCD16+ NK cells as rapid producers of abundant IFN- $\gamma$ on activation," Proceedings of the National Academy of Sciences of the United States of America, vol. 108, no. 2, pp. 728-732, 2011.

[79] L. Moretta, G. Ferlazzo, C. Bottino et al., "Effector and regulatory events during natural killer-dendritic cell interactions," Immunological Reviews, vol. 214, no. 1, pp. 219-228, 2006.

[80] M. A. Cooper, T. A. Fehniger, A. Fuchs, M. Colonna, and M. A. Caligiuri, "NK cell and DC interactions," Trends in Immunology, vol. 25, no. 1, pp. 47-52, 2004.
[81] T. Musso, L. Calosso, M. Zucca et al., "Human monocytes constitutively express membrane-bound, biologically active, and interferon- $\gamma$-upregulated interleukin-15," Blood, vol. 93, no. 10, pp. 3531-3539, 1999.

[82] J. P. Lodolce, P. R. Burkett, D. L. Boone, M. Chien, and A. Ma, "T cell-independent interleukin $15 \mathrm{R} \alpha$ signals are required for bystander proliferation," Journal of Experimental Medicine, vol. 194, no. 8, pp. 1187-1193, 2001.

[83] S. W. Stonier and K. S. Schluns, "Trans-presentation: a novel mechanism regulating IL-15 delivery and responses," Immunology Letters, vol. 127, no. 2, pp. 85-92, 2010.

[84] S. Dubois, J. Mariner, T. A. Waldmann, and Y. Tagaya, "IL$15 \mathrm{R} \alpha$ recycles and presents IL-15 in trans to neighboring cells," Immunity, vol. 17, no. 5, pp. 537-547, 2002.

[85] J. Giron-Michel, M. Giuliani, M. Fogli et al., "Membranebound and soluble IL-15/IL-15R $\alpha$ complexes display differential signaling and functions on human hematopoietic progenitors," Blood, vol. 106, no. 7, pp. 2302-2310, 2005.

[86] E. Mortier, T. Woo, R. Advincula, S. Gozalo, and A. Ma, "IL$15 \mathrm{R} \alpha$ chaperones IL-15 to stable dendritic cell membrane complexes that activate NK cells via trans presentation," Journal of Experimental Medicine, vol. 205, no. 5, pp. 12131225, 2008.

[87] R. Koka, P. R. Burkett, M. Chien et al., "Interleukin (IL)$15 \mathrm{R} \alpha$-deficient natural killer cells survive in normal but not IL-15R $\alpha$-deficient mice," Journal of Experimental Medicine, vol. 197, no. 8, pp. 977-984, 2003.

[88] T. Kawamura, R. Koka, A. Ma, and V. Kumar, "Differential roles for IL-15R alpha-chain in NK cell development and Ly49 induction," Journal of Immunology, vol. 171, no. 10, pp. 5085-5090, 2003.

[89] E. Mortier, R. Advincula, L. Kim et al., "Macrophage- and dendritic-cell-derived interleukin-15 receptor alpha supports homeostasis of distinct CD8+ T cell subsets," Immunity, vol. 31, no. 5, pp. 811-822, 2009.

[90] N. D. Huntington, N. Legrand, N. L. Alves et al., "IL-15 trans-presentation promotes human NK cell development and differentiation in vivo," Journal of Experimental Medicine, vol. 206, no. 1, pp. 25-34, 2009.

[91] S. K. Olsen, N. Ota, S. Kishishita et al., "Crystal structure of the interleukin-15-interleukin-15 receptor $\alpha$ complex: insights into trans and cis presentation," Journal of Biological Chemistry, vol. 282, no. 51, pp. 37191-37204, 2007.

[92] R. Zambello, M. Facco, L. Trentin et al., "Interleukin15 triggers the proliferation and cytotoxicity of granular lymphocytes in patients with lymphoproliferative disease of granular lymphocytes," Blood, vol. 89, no. 1, pp. 201-211, 1997.

[93] T. A. Fehniger, K. Suzuki, A. Ponnappan et al., "Fatal leukemia in interleukin 15 transgenic mice follows early expansions in natural killer and memory phenotype CD8+ T cells," Journal of Experimental Medicine, vol. 193, no. 2, pp. 219-231, 2001.

[94] G. G. Neely, S. Epelman, L. L. Ma et al., "Monocyte surfacebound IL-15 can function as an activating receptor and participate in reverse signaling," Journal of Immunology, vol. 172, no. 7, pp. 4225-4234, 2004.

[95] M. Giuliani, J. Giron-Michel, S. Negrini et al., "Generation of a novel regulatory NK cell subset from peripheral blood CD34+ progenitors promoted by membrane-bound IL-15," PLoS One, vol. 3, no. 5, Article ID e2241, 16 pages, 2008.

[96] S. Negrini, M. Giuliani, D. Durali, S. Chouaib, and B. Azzarone, "Membrane-bound IL-15 stimulation on peripheral blood NK progenitors (PB-NKp) leads to the generation 
of an adherent subset co-expressing DC and NK functional markers," Haematologica, vol. 96, no. 5, pp. 2762-2766, 2011.

[97] V. Budagian, E. Bulanova, Z. Orinska et al., "Natural soluble interleukin-15R $\alpha$ is generated by cleavage that involves the tumor necrosis factor- $\alpha$-converting enzyme (TACE/ADAM17)," Journal of Biological Chemistry, vol. 279, no. 39, pp. 40368-40375, 2004.

[98] E. Mortier, J. Bernard, A. Plet, and Y. Jacques, "Natural, proteolytic release of a soluble form of human IL-15 receptor $\alpha$-chain that behaves as a specific, high affinity IL-15 antagonist," Journal of Immunology, vol. 173, no. 3, pp. 1681$1688,2004$.

[99] E. Mortier, A. Quéméner, P. Vusio et al., "Soluble interleukin15 receptor alpha (IL-15R alpha)-sushi as a selective and potent agonist of IL-15 action through IL-15R beta/gamma. Hyperagonist IL-15 x IL-15R alpha fusion proteins," Journal of Biological Chemistry, vol. 281, no. 3, pp. 1612-1619, 2006.

[100] H. Perdreau, E. Mortier, G. Bouchaud et al., "Different dynamics of IL-15R activation following IL-15 cis- or transpresentation," European Cytokine Network, vol. 21, no. 4, pp. 297-307, 2010.

[101] R. B. Herberman and H. T. Holden, "Natural cell-mediated immunity," Advances in Cancer Research, vol. 27, pp. 305377, 1978.

[102] M. A. Cooper and W. M. Yokoyama, "Memory-like responses of natural killer cells," Immunological Reviews, vol. 235, no. 1, pp. 297-305, 2010.

[103] E. Vivier, D. H. Raulet, A. Moretta et al., "Innate or adaptive immunity? The example of natural killer cells," Science, vol. 331, no. 6013, pp. 44-49, 2011.

[104] J. G. O’Leary, M. Goodarzi, D. L. Drayton, and U. H. von Andrian, "T cell- and B cell-independent adaptive immunity mediated by natural killer cells," Nature Immunology, vol. 7, no. 5, pp. 507-516, 2006.

[105] M. A. Cooper, J. M. Elliott, P. A. Keyel, L. Yang, J. A. Carrero, and W. M. Yokoyama, "Cytokine-induced memorylike natural killer cells," Proceedings of the National Academy of Sciences of the United States of America, vol. 106, no. 6, pp. 1915-1919, 2009.

[106] M. Lucas, W. Schachterle, K. Oberle, P. Aichele, and A. Diefenbach, "Dendritic cells prime natural killer cells by trans-presenting interleukin 15," Immunity, vol. 26, no. 4, pp. 503-517, 2007.

[107] M. C. Mingari, C. Vitale, C. Cantoni et al., "Interleukin-15induced maturation of human natural killer cells from early thymic precursors: selective expression of CD94/NKG2-A as the only HLA class I-specific inhibitory receptor," European Journal of Immunology, vol. 27, no. 6, pp. 1374-1380, 1997.

[108] C. A. J. Vosshenrich, M. E. García-Ojeda, S. I. SamsonVilléger et al., "A thymic pathway of mouse natural killer cell development characterized by expression of GATA-3 and CD127," Nature Immunology, vol. 7, no. 11, pp. 1217-1224, 2006.

[109] A. G. Freud, B. Becknell, S. Roychowdhury et al., "A human $\mathrm{CD} 34(+)$ subset resides in lymph nodes and differentiates into CD56 natural killer cells," Immunity, vol. 22, no. 3, pp. 295-304, 2005.

[110] S. L. Sanos, V. L. Bui, A. Mortha et al., "ROR $y$ t and commensal microflora are required for the differentiation of mucosal interleukin 22-producing NKp46 cells," Nature Immunology, vol. 10, no. 1, pp. 83-91, 2009.

[111] E. Vivier, H. Spits, and T. Cupedo, "Interleukin-22producing innate immune cells: new players in mucosal immunity and tissue repair?" Nature Reviews Immunology, vol. 9, no. 4, pp. 229-234, 2009.

[112] M. Cella, A. Fuchs, W. Vermi et al., "A human natural killer cell subset provides an innate source of IL-22 for mucosal immunity," Nature, vol. 457, no. 7230, pp. 722-725, 2009.

[113] L. Moretta and A. Moretta, "Unravelling natural killer cell function: triggering and inhibitory human NK receptors," EMBO Journal, vol. 23, no. 2, pp. 255-259, 2004.

[114] T. Hughes, B. Becknell, S. McClory et al., "Stage 3 immature human natural killer cells found in secondary lymphoid tissue constitutively and selectively express the T17 cytokine interleukin-22," Blood, vol. 113, no. 17, pp. 4008-4010, 2009.

[115] B. Grzywacz, N. Kataria, N. Kataria, B. R. Blazar, J. S. Miller, and M. R. Verneris, "Natural killer cell differentiation by myeloid progenitors," Blood, vol. 117, no. 13, pp. 3548-3558, 2011.

[116] S. A. Perez, P. A. Sotiropoulou, D. G. Gkika et al., "A novel myeloid-like NK cell progenitor in human umbilical cord blood," Blood, vol. 101, no. 9, pp. 3444-3450, 2003.

[117] P. Vacca, C. Vitale, E. Montaldo et al., "CD34+ hematopoietic precursors are present in human decidua and differentiate into natural killer cells upon interaction with stromal cells," Proceedings of the National Academy of Sciences of the United States of America, vol. 108, no. 6, pp. 2402-2407, 2011.

[118] J. Brady, Y. Hayakawa, M. J. Smyth, and S. L. Nutt, "IL21 induces the functional maturation of murine NK cells," Journal of Immunology, vol. 172, no. 4, pp. 2048-2058, 2004.

[119] J. M. Roda, T. Joshi, J. P. Butchar et al., "The activation of natural killer cell effector functions by cetuximab-coated, epidermal growth factor receptor-positive tumor cells is enhanced by cytokines," Clinical Cancer Research, vol. 13, no. 21, pp. 6419-6428, 2007.

[120] M. Watanabe, K. Kono, Y. Kawaguchi et al., "Interleukin21 can efficiently restore impaired antibody-dependent cellmediated cytotoxicity in patients with oesophageal squamous cell carcinoma," British Journal of Cancer, vol. 102, no. 3, pp. 520-529, 2010.

[121] J. Parrish-Novak, D. C. Foster, R. D. Holly, and C. H. Clegg, "Interleukin-21 and the IL-21 receptor: novel effectors of NK and T cell responses," Journal of Leukocyte Biology, vol. 72, no. 5, pp. 856-863, 2002.

[122] J. A. Toomey, F. Gays, D. Foster, and C. G. Brooks, "Cytokine requirements for the growth and development of mouse NK cells in vitro," Journal of Leukocyte Biology, vol. 74, no. 2, pp. 233-242, 2003.

[123] M. T. Kasaian, M. J. Whitters, L. L. Carter et al., "IL-21 limits NK cell responses and promotes antigen-specific T cell activation: a mediator of the transition from innate to adaptive immunity," Immunity, vol. 16, no. 4, pp. 559-569, 2002.

[124] R. Takaki, Y. Hayakawa, A. Nelson et al., "IL-21 enhances tumor rejection through a NKG2D-dependent mechanism," Journal of Immunology, vol. 175, no. 4, pp. 2167-2173, 2005.

[125] S. J. Burgess, A. I. Marusina, I. Pathmanathan, F. Borrego, and J. E. Coligan, "IL-21 down-regulates NKG2D/DAP10 expression on human NK and CD8+ T cells," Journal of Immunology, vol. 176, no. 3, pp. 1490-1497, 2006.

[126] S. Sivori, C. Cantoni, S. Parolini et al., "IL-21 induces both rapid maturation of human CD34 cell precursors towards NK cells and acquisition of surface killer Ig-like receptors," European Journal of Immunology, vol. 33, no. 12, pp. 34393447, 2003.

[127] G. Bonanno, A. Mariotti, A. Procoli et al., "Interleukin-21 induces the differentiation of human umbilical cord blood 
CD34-lineagecells into pseudomature lytic NK cells," BMC Immunology, vol. 10, Article ID 1471, p. 46, 2009.

[128] M. B. Atkins, M. T. Lotze, J. P. Dutcher et al., "Highdose recombinant interleukin 2 therapy for patients with metastatic melanoma: analysis of 270 patients treated between 1985 and 1993," Journal of Clinical Oncology, vol. 17, no. 7, pp. 2105-2116, 1999.

[129] M. Rosenstein, S. E. Ettinghausen, and S. A. Rosenberg, "Extravasation of intravascular fluid mediated by the systemic administration of recombinant interleukin 2," Journal of Immunology, vol. 137, no. 5, pp. 1735-1742, 1986.

[130] C. M. Capitini, T. J. Fry, and C. L. Mackall, "Cytokines as adjuvants for vaccine and cellular therapies for cancer," American Journal of Immunology, vol. 5, no. 3, pp. 65-83, 2009.

[131] N. M. Fewkes and C. L. Mackall, "Novel gamma-chain cytokines as candidate immune modulators in immune therapies for cancer," Cancer Journal, vol. 16, no. 4, pp. 392-398, 2010.

[132] E. Di Carlo, R. Meazza, S. Basso et al., "Dissimilar antitumour reactions induced by tumour cells engineered with the interleukin-2 or interleukin-15 gene in nude mice," Journal of Pathology, vol. 191, no. 2, pp. 193-201, 2000.

[133] R. Meazza, P. L. Lollini, P. Nanni et al., "Gene transfer of a secretable form of IL-15 in murine adenocarcinoma cells: effects on tumorigenicity, metastatic potential and immune response," International Journal of Cancer, vol. 87, no. 4, pp. 574-581, 2000.

[134] W. Munger, S. Q. Dejoy, R. Jeyaseelan et al., "Studies evaluating the antitumor activity and toxicity of interleukin-15, a new T cell growth factor: comparison with interleukin-2," Cellular Immunology, vol. 165, no. 2, pp. 289-293, 1995.

[135] A. Arina, O. Murillo, J. Dubrot et al., "Interleukin-15 liver gene transfer increases the number and function of IKDCs and NK cells," Gene Therapy, vol. 15, no. 7, pp. 473-483, 2008.

[136] E. Lugli, C. K. Goldman, L. P. Perera et al., "Transient and persistent effects of IL-15 on lymphocyte homeostasis in nonhuman primates," Blood, vol. 116, no. 17, pp. 3238-3248, 2010.

[137] A. Kroemer, X. Xiao, N. Degauque et al., "The innate NK cells, allograft rejection, and a key role for IL-15," Journal of Immunology, vol. 180, no. 12, pp. 7818-7826, 2008.

[138] L. Moretta, F. Locatelli, D. Pende, E. Marcenaro, M. C. Mingari, and A. Moretta, "Killer Ig-like receptor-mediated control of natural killer cell alloreactivity in haploidentical hematopoietic stem cell transplantation," Blood, vol. 117, no. 3, pp. 764-771, 2011.

[139] H. Fujisaki, H. Kakuda, N. Shimasaki et al., "Expansion of highly cytotoxic human natural killer cells for cancer cell therapy," Cancer Research, vol. 69, no. 9, pp. 4010-4017, 2009.

[140] A. Comes, O. Rosso, A. M. Orengo et al., "CD25 regulatory T cell depletion augments immunotherapy of micrometastases by an IL-21-secreting cellular vaccine," Journal of Immunology, vol. 176, no. 3, pp. 1750-1758, 2006.

[141] R. Spolski and W. J. Leonard, "IL-21 Is an immune activator that also mediates suppression via IL-10," Critical Reviews in Immunology, vol. 30, no. 6, pp. 559-570, 2010.

[142] E. Di Carlo, D. De Totero, T. Piazza, M. Fabbi, and S. Ferrini, "Role of IL-21 in immune-regulation and tumor immunotherapy," Cancer Immunology, Immunotherapy, vol. 56, no. 9, pp. 1323-1334, 2007.
[143] D. J. Andorsky and J. M. Timmerman, "Interleukin-21: biology and application to cancer therapy," Expert Opinion on Biological Therapy, vol. 8, no. 9, pp. 1295-1307, 2008.

[144] E. Di Carlo, A. Comes, A. M. Orengo et al., "IL-21 induces tumor rejection by specific CTL and IFN-gamma-dependent CXC chemokines in syngeneic mice," Journal of Immunology, vol. 172, no. 3, pp. 1540-1547, 2004.

[145] S. I. Ugai, O. Shimozato, L. Yu et al., "Transduction of the IL21 and IL-23 genes in human pancreatic carcinoma cells produces natural killer cell-dependent and -independent antitumor effects," Cancer Gene Therapy, vol. 10, no. 10, pp. 771778, 2003.

[146] M. Croce, R. Meazza, A. M. Orengo et al., "Immunotherapy of neuroblastoma by an Interleukin-21-secreting cell vaccine involves survivin as antigen," Cancer Immunology, Immunotherapy, vol. 57, no. 11, pp. 1625-1634, 2008.

[147] M. Croce, M. V. Corrias, A. M. Orengo et al., "Transient depletion of CD4+ $\mathrm{T}$ cells augments IL-21-based immunotherapy of disseminated neuroblastoma in syngeneic mice," International Journal of Cancer, vol. 127, no. 5, pp. 11411150, 2010.

[148] G. Wang, M. Tschoi, R. Spolski et al., "In vivo antitumor activity of interleukin 21 mediated by natural killer cells," Cancer Research, vol. 63, no. 24, pp. 9016-9022, 2003.

[149] T. Kishida, H. Asada, Y. Itokawa et al., "Interleukin (IL)21 and IL-15 genetic transfer synergistically augments therapeutic antitumor immunity and promotes regression of metastatic lymphoma," Molecular Therapy, vol. 8, no. 4, pp. 552-558, 2003.

[150] C. R. Ferrone, M. A. Perales, S. M. Goldberg et al., "Adjuvanticity of plasmid DNA encoding cytokines fused to immunoglobulin Fc domains," Clinical Cancer Research, vol. 12, no. 18, pp. 5511-5519, 2006.

[151] I. D. Davis, B. K. Skrumsager, J. Cebon et al., "An open-label, two-arm, phase I trial of recombinant human interleukin21 in patients with metastatic melanoma," Clinical Cancer Research, vol. 13, no. 12, pp. 3630-3636, 2007.

[152] J. A. Thompson, B. D. Curti, B. G. Redman et al., "Phase I study of recombinant interleukin-21 in patients with metastatic melanoma and renal cell carcinoma," Journal of Clinical Oncology, vol. 26, no. 12, pp. 2034-2039, 2008.

[153] H. Schmidt, J. Brown, U. Mouritzen et al., "Safety and clinical effect of subcutaneous human interleukin-21 in patients with metastatic melanoma or renal cell carcinoma: a phase I trial," Clinical Cancer Research, vol. 16, no. 21, pp. 5312-5319, 2010.

[154] I. D. Davis, B. Brady, R. F. Kefford et al., "Clinical and biological efficacy of recombinant human interleukin-21 in patients with stage TV Malignant melanoma without prior treatment: a phase Lla trial," Clinical Cancer Research, vol. 15, no. 6, pp. 2123-2129, 2009.

[155] A. Gowda, A. Ramanunni, C. Cheney et al., "Differential effects of IL-2 and IL-21 on expansion of the CD4+CD25+Foxp3+ T regulatory cells with redundant roles in natural killer cell mediated antibody dependent cellular cytotoxicity in chronic lymphocytic leukemia," $m A b s$, vol. 2, no. 1, pp. 35-41, 2010.

[156] J. Timmerman, C. Byrd, and D. J. Andorsky, "Efficacy and safety of recombinant interleukin-21 and rituximab in relapse/refractory indolent lymphoma," Journal of Clinical Oncology, vol. 26, supplement, 2008, abstract 8554.

[157] A. Iannello, M. R. Boulassel, S. Samarani et al., "IL-21 enhances NK cell functions and survival in healthy and 
HIV-infected patients with minimal stimulation of viral replication," Journal of Leukocyte Biology, vol. 87, no. 5, pp. 857-867, 2010.

[158] N. Strbo, L. De Armas, H. Liu, M. A. Kolber, M. Lichtenheld, and S. Pahwa, "IL-21 augments natural killer effector functions in chronically HIV-infected individuals," AIDS, vol. 22, no. 13, pp. 1551-1560, 2008.

[159] A. I. Daud, R. C. DeConti, S. Andrews et al., "Phase I trial of interleukin-12 plasmid electroporation in patients with metastatic melanoma," Journal of Clinical Oncology, vol. 26, no. 36, pp. 5896-5903, 2008.

[160] H. N. Lode, R. Xiang, J. C. Becker, S. D. Gillies, and R. A. Reisfeld, "Immunocytokines: a promising approach to cancer immunotherapy," Pharmacology and Therapeutics, vol. 80, no. 3, pp. 277-292, 1998.

[161] B. Carnemolla, L. Borsi, E. Balza et al., "Enhancement of the antitumor properties of interleukin-2 by its targeted delivery to the tumor blood vessel extracellular matrix," Blood, vol. 99, no. 5, pp. 1659-1665, 2002.

[162] M. Johannsen, G. Spitaleri, G. Curigliano et al., "The tumour-targeting human L19-IL2 immunocytokine: preclinical safety studies, phase I clinical trial in patients with solid tumours and expansion into patients with advanced renal cell carcinoma," European Journal of Cancer, vol. 46, no. 16, pp. 2926-2935, 2010.

[163] Z. C. Neal, M. Imboden, A. L. Rakhmilevich et al., "NXS2 murine neuroblastomas express increased levels of MHC class I antigens upon recurrence following NK-dependent immunotherapy," Cancer Immunology, Immunotherapy, vol. 53, no. 1, pp. 41-52, 2004.

[164] M. V. Corrias, M. Occhino, M. Croce et al., "Lack of HLAclass I antigens in human neuroblastoma cells: analysis of its relationship to TAP and tapasin expression," Tissue Antigens, vol. 57, no. 2, pp. 110-117, 2001.

[165] R. Castriconi, A. Dondero, M. V. Corrias et al., "Natural killer cell-mediated killing of freshly isolated neuroblastoma cells: critical role of DNAX accessory molecule-1-poliovirus receptor interaction," Cancer Research, vol. 64, no. 24, pp. 9180-9184, 2004.

[166] D. C. Delgado, J. A. Hank, J. Kolesar et al., "Genotypes of NK cell KIR receptors, their ligands, and Fc $\gamma$ receptors in the response of neuroblastoma patients to Hu14.18-IL2 immunotherapy," Cancer Research, vol. 70, no. 23, pp. 95549561, 2010. 


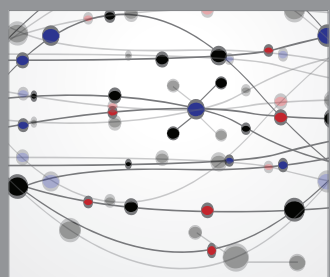

The Scientific World Journal
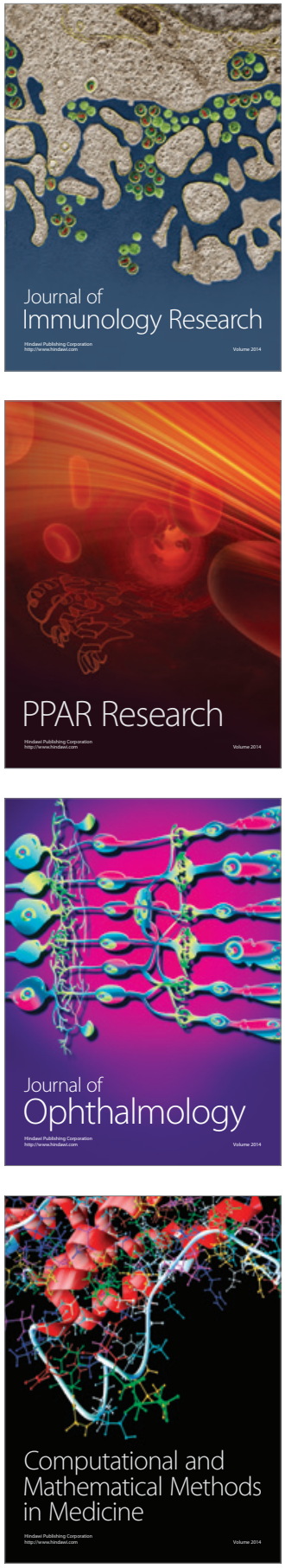

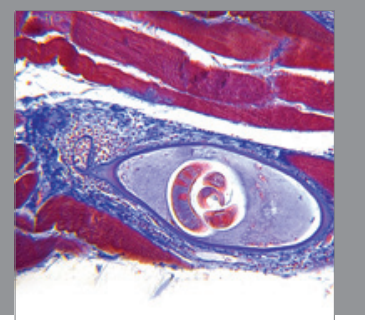

Gastroenterology

Research and Practice
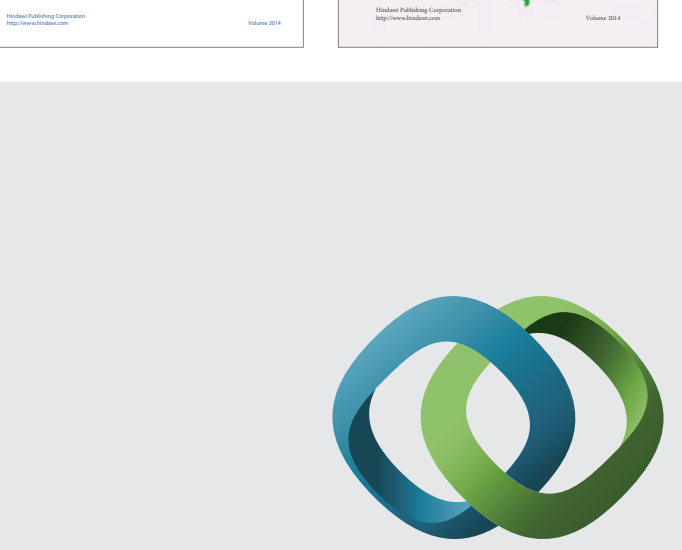

\section{Hindawi}

Submit your manuscripts at

http://www.hindawi.com
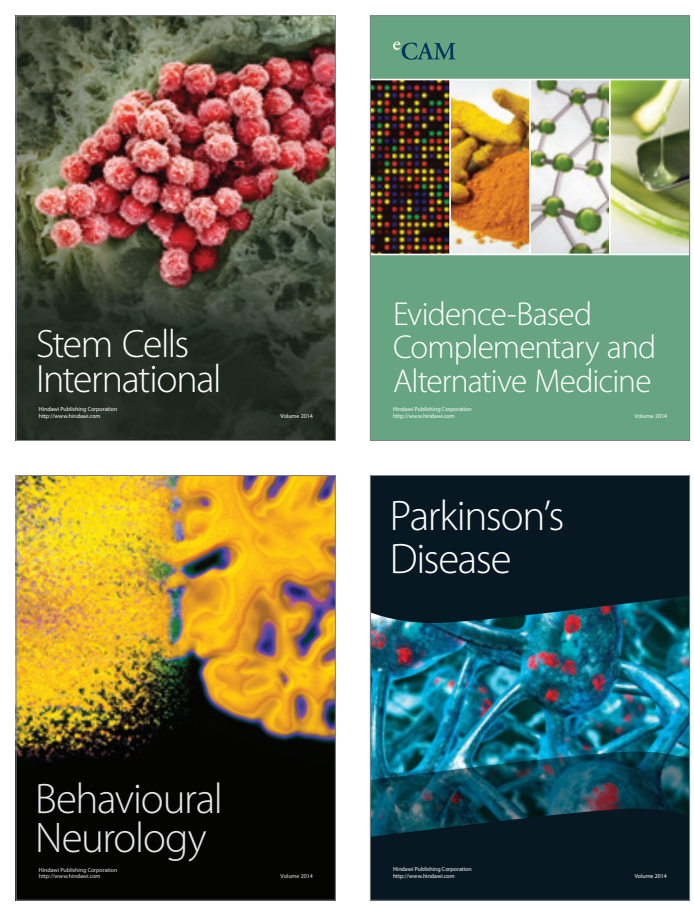

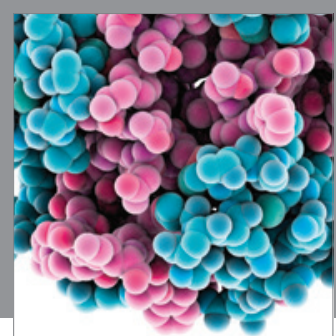

Journal of
Diabetes Research

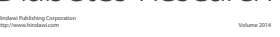

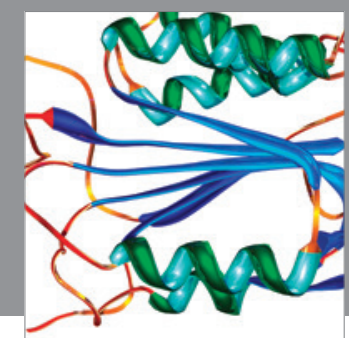

Disease Markers
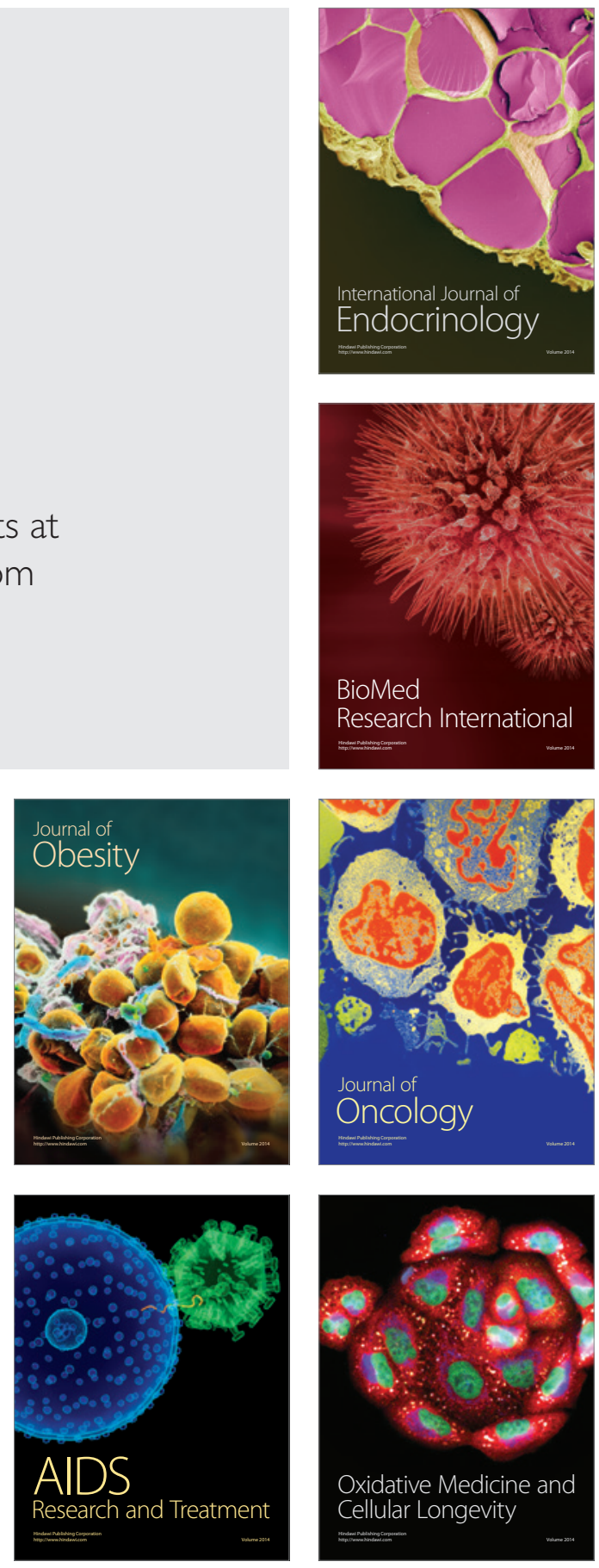